
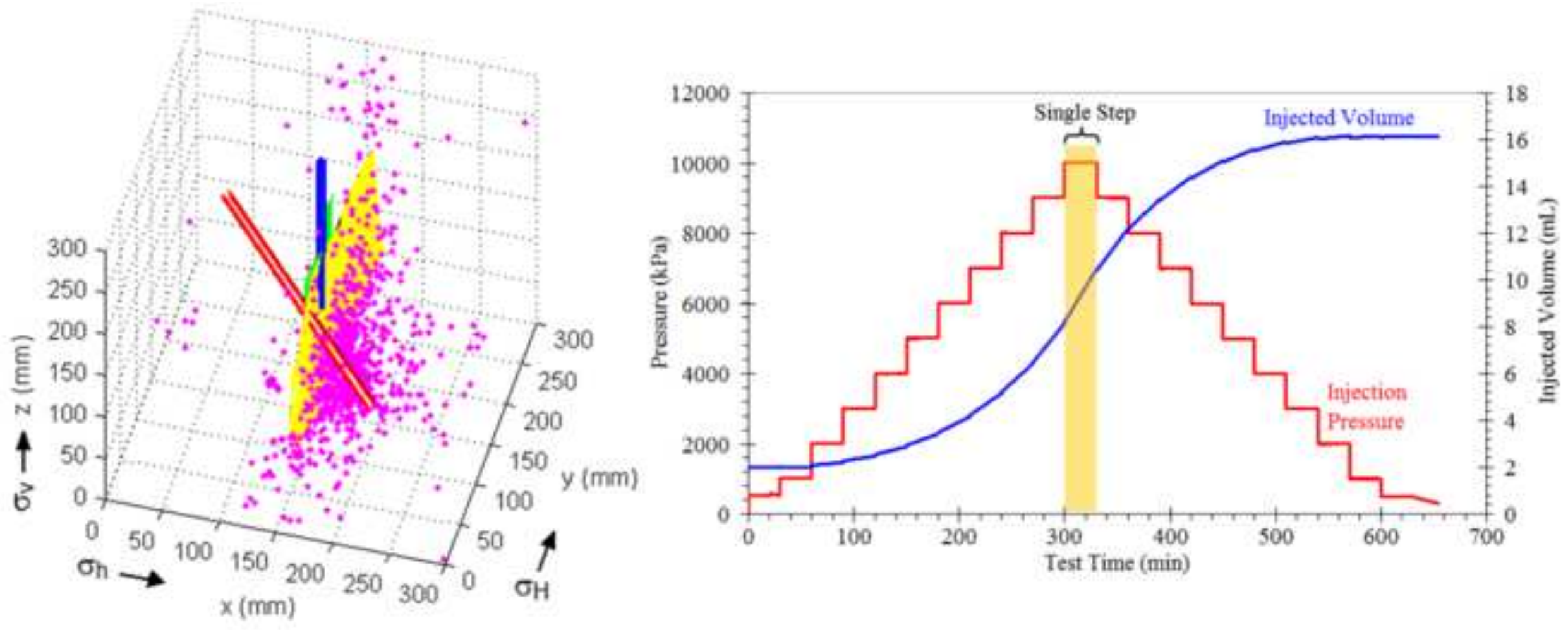


0

\title{
Laboratory simulation of binary and triple well EGS in large granite blocks using AE events for drilling guidance
}

\author{
Luke P. Frash ${ }^{1}$, Marte Gutierrez ${ }^{1,2}$, Jesse Hampton ${ }^{1}$ and John Hood ${ }^{1}$ \\ ${ }^{1}$ Colorado School of Mines, Golden, CO 80401, USA \\ ${ }^{2}$ Khalifa University, Abu Dhabi, UAE
}

Corresponding Author: Luke Frash, lfrash@mines.edu, 1 (303) 305-8834

\begin{abstract}
\end{abstract}

$$
\text { Multiple-well Enhanced Geothermal Systems (EGS) can enable economic }
$$
recovery of energy from underutilized hot dry rock (HDR) reservoirs. Hydraulic fracturing is a promising stimulation method for improving fluid flow and heat extraction in EGS. Laboratory simulations of EGS with hydraulic fracture stimulation have recently been completed in two large $300 \times 300 \times 300 \mathrm{~mm}^{3}$ granite block specimens to better understand this complex process of geothermal energy recovery. The first experiment implemented a binary well layout with an injector and producer. The second experiment used a triplet well layout with one injector and two producers. Selection of production well trajectory so as to intersect the hydraulic fractures was guided by acoustic emission (AE) events collected during stimulation. Both model reservoirs were subjected to heating and true-triaxial stress confinement throughout a series of drilling, stimulation, and flow and heat circulation tests. Stimulated thermal reservoir flow was characterized by a series of constant pressure, constant flow rate, stepped constant pressure and stepped constant flow rate injection tests. Tested blocks were cross-sectioned to characterize final locations and 3D geometries of the induced fractures. Insights and lessons learned from these experiments are presented with focus on application to field-scale EGS.

Keywords: Enhanced Geothermal Systems (EGS), Hydraulic Fracture, Acoustic Emission (AE), Discontinuities, Fracture Flow 


\section{Introduction}

Enhanced Geothermal Systems (EGS) have the potential to enable economic

30 recovery of energy from underutilized hot dry rock (HDR) reservoirs or increase

31 production from conventional geothermal reservoirs (Tester et al., 2006). The basis of

32 EGS involves drilling an array of injection and production wells into a target hot-rock

33 reservoir and stimulating the reservoir to improve in-situ permeability. This allows for

34 sustained injection and circulation of fluid through the reservoir for commercial

35 extraction of heat energy, a process also referred to as geothermal heat-mining. Hydraulic

36 fracturing offers a means for stimulation where fluids are injected with sufficient rate and

37 pressure to create new fractures. EGS is intended for implementation in deep high-

38 temperature rocks which have complex geologic structures and contain significant

39 thermal energy. However, experience with hydraulic fracturing in abundant crystalline

40 HDRs, such as granites and diorites, is limited in comparison with sedimentary

41 applications common to the oil and gas industry.

42 Research to advance EGS and hydraulic fracturing technology has included

43 modeling efforts, laboratory experiments and field scale tests (GTO, 2014; Tester et al.,

44 2006; Valkó and Economides, 1995). One topic that remains uncertain through the

45 existing research is a strong understanding of how hydraulic fractures propagate through

46 complex crystalline rocks, how actual prominent fracture locations relate to acoustic

47 emission (AE) source locations, and how fluid flows through hydraulically stimulated

48 fractures between wells (Warpinski et al., 1987). Laboratory experiments can offer

49 insight on these questions as a benefit of physical data collected in controlled conditions

50 using measurement and monitoring capabilities beyond what is possible at the field scale. 
51 Relevant laboratory experiments have included hydraulic fracturing studies (Abass et al.,

52 1996; Behrmann and Elbel, 1991; de Pater et al., 1994; Haimson and Zhao, 1991; Hallam

53 and Last, 1991; Ishida et al., 2004; Warpinski et al., 1982) and fracture conductivity tests

54 (API RP61, 1989). These studies, to the best knowledge of the authors, mostly neglect

55 thermal effects, use ideal or sedimentary rock specimens, do not incorporate multi-

56 borehole systems and coarsely inspect the final fracture geometry. A comprehensive

57 study which includes these experiment parameters and meticulously investigates created

58 fracture geometry, through cross-sections paired with AE, is expected to offer beneficial

59 insights building on previous studies. The results from such as study are expected to

60 improve understanding of the difficulties with applying EGS to crystalline HDR and the

61 respective causes of these difficulties. This understanding can be applied to the field-

62 scale where similar measurements are not possible but similar fracturing and fluid flow

63 behavior can be assumed or inferred.

64 Comprehensive laboratory experiments were recently conducted in an effort to

65 improve understanding of multiple-well EGS reservoirs in crystalline HDR. Two large

$66300 \times 300 \times 300 \mathrm{~mm}^{3}$ granite blocks were subjected to HDR conditions and hydraulically

67 fractured to create EGS models. A binary well configuration with one injector and one

68 producer was implemented for the first experiment. The second experiment used a triplet

69 configuration with an injector and two production wells. In both experiments, production

70 well trajectories were selected so as to intersect the main hydraulic fracture wings using

71 acoustic emission (AE) event source locations collected during stimulation. Both rock

72 specimens were subjected to heating and true-triaxial stress confinement throughout

73 drilling, stimulation and production operations. Simulation methods included 
74 conventional hydraulic fracturing, hydraulic re-fracturing and mechanical impulse

75 stimulation. Treatment schedules for each test were tailored according to the observed

76 response of the reservoir to successive injection and circulation treatments. Well

77 injectivity and productivity was characterized by a series of repeated fluid injection tests.

78 Creation of EGS reservoirs was successful in both experiments but the need for

79 improvement to the stimulation process and well design was also apparent. Suggestions

80 are presented for future EGS design following lessons learned from these experiments.

\section{2. EGS Simulation Methodology}

82 Details on the test materials, equipment and procedures used for this study are

83 provided in this section. Fluid flow data collected during experiments were synthesized to

84 representative values following the methods described in this section to enable direct

85 comparison of results.

86 2.1. Rock Specimen Characteristics

87 Granite specimens were obtained from the Liesveld Quarry in Lyons, Colorado.

88 The specimens were extracted from an outcrop using water jet cutting and trimmed to

$89300 \times 300 \times 300 \mathrm{~mm}^{3}$ cubes by diamond wire sawing. This specimen preparation process

90 minimized mechanical damage. Supplemental element tests were performed to

91 characterize the rock properties following relevant ASTM standards with the exact

92 procedures detailed in Frash (2012). The respective results are shown in Table 1. The

93 granite specimens typically exhibited low-porosity and low-permeability so matrix leak-

94 off during fluid injection was expected to be negligible. Pre-stimulation well injectivity

95 tests were performed for improved evaluation of stimulation effects. 
The dominant minerals in the granite were quartz and feldspar with minor biotite

97 and muscovite. The grains of the granite were heterogeneous in size and distribution as is

98 common for natural rocks. Typical grain sizes ranged from less than $0.0005 \mathrm{~mm}$ up to 15

$99 \mathrm{~mm}$ in length, measured by photomicrographs and calipers. Large grains contained

100 striations and composite structures making precise definition of grain size difficult. This

101 difficulty is common in heterogeneous rocks and remains a topic of active research in

102 regards to characterizing materials for modeling. Fig. 1 shows a typical photomicrograph

103 of the granite's heterogeneous grains. This heterogeneity was preferred for these EGS

104 experiments because real rock has a potential for producing more complex results than

105 idealized materials. Complex results can in-turn offer insight for field-scale EGS where

106 heterogeneity and discontinuities are a fact of nature.

\section{2.2. True-Triaxial Equipment}

108 A true-triaxial apparatus was used to apply heating and confining stresses to the

109 cubical rock specimens. Stresses were applied by an assembly of flat jacks and platens as

110 shown in Fig. 2. Heating was applied by external electrical elements with constant

111 temperature control. Passive platens enabled drilling of multiple wells at orientations

112 ranging from vertical through horizontal. The maximum confinement stress provided by

113 the apparatus was $13 \mathrm{MPa}$ and the maximum proof temperature was $100{ }^{\circ} \mathrm{C}$. Data

114 monitoring systems included pressure transducers, thermocouples, strain gages, and six

115 Acoustic Emission (AE) sensors. Capability for pore pressure application and control at

116 the boundary of the specimen was not incorporated into this equipment because HDR

117 conditions were intended. Additional details on the equipment and instrumentation can be

118 found in Frash (2012), and Frash et al. (2013b). 


\subsection{Injection Fluids and Equipment}

$120 \quad$ Fluids injected for stimulation and flow testing included Valvoline ${ }^{\circledR}$ DuraBlend ${ }^{\circledR}$

121 SAE 80W90 gear oil and tap water. Estimated properties for these liquids at selected

122 temperatures are shown in Table 2 (ASTM D341, 2009; Valvoline, 2012; White, 2009).

123 Gear oil was used for hydraulic fracturing and water was used for most injection flow

124 testing. Oil was chosen for its high viscosity relative to water. Previous studies suggest

125 higher viscosity fluids are beneficial for laboratory hydraulic fracturing with respect to

126 scaling laws (de Pater et al., 1994) and creation of less tortuous fracture pathways (Ishida

127 et al., 2004). It was assumed that more ideal planar bi-wing hydraulic fracture geometries

128 would result with increased fluid conductivity between the injection and production wells

129 during EGS fluid flow testing. Water was used for injectivity testing to allow increased

130 flow rates without an associated increased risk of additional stimulation as can occur with

131 high-viscosity fluid injection. Water also gave the advantage of well-known thermo-

132 mechanical properties (White, 2009). Tap water was selected because it was anticipated

133 that dissolved minerals would buffer chemical reaction with minerals in the granite. No

134 significant chemical dissolution or precipitation was observed in post-test cross-sections

135 indicating that fluid residence times and chemical buffering were sufficient to neglect 136 geochemical effects.

137 Hydraulic injection equipment included two Teledyne Isco 65DM syringe pumps, 138 a vacuum pump, a computer control system with automated valves, and a combination of 139 injection and production wells. A basic diagram of this hydraulic system is presented in

140 Fig. 3. Drilling of the injection well was executed in two stages while the rock specimen

141 was maintained at heated and confined conditions. The upper interval of the well was 
142 drilled at $10 \mathrm{~mm}$ diameter and cased with $9.8 \mathrm{~mm}$ O.D. 316 stainless steel tubing having

$1436.4 \mathrm{~mm}$ I.D. The casing was sealed for high pressure injection by filling the annulus

144 between rock and casing with epoxy grout. Threads were cut on the outside of the casing

145 wall to improve seal strength. A lower open injection interval (uncased) was drilled at 5.6

$146 \mathrm{~mm}$ diameter after the epoxy grout fully cured. Production wells were drilled open at 10

$147 \mathrm{~mm}$ diameter and sealed for vacuum pumping. Vacuum sealing was provided by a 9.8

148 mm O.D. vinyl sleeve overlying a $6.4 \mathrm{~mm}$ O.D. nylon tube. A copper ferrule fixed to the

149 nylon tube was pulled into the sleeve to expand the vinyl into the well annulus forming a

150 sealed ring. Produced fluids were pumped through a condenser and respective flow rates

151 into an outflow fluid reservoir were measured with a digital mass balance.

\section{2.4. Hydraulic Stimulation Procedures}

153 Multiple hydraulic stimulation procedures were applied to create permeable fluid

154 flow pathways through the granite specimens and to link injector and producer wells to

155 these pathways. Stimulation injections included conventional hydraulic fracturing,

156 hydraulic fracture re-stimulation and mechanical impulse hydraulic fracturing (MIF).

157 Conventional hydraulic fracturing and re-fracturing was performed by injecting

158 fluid at constant flow (CF) rate. Idealized pressure and flow rate curves are shown in Fig.

159 4. In this figure, $P$ is the injection well pressure, $Q$ is the fluid injection rate, $P_{0}$ is the

160 reservoir pore pressure, $P_{b}$ is the initial fracture breakdown pressure, $P_{s}$ is the fracture

161 shut-in pressure or fracture closure pressure, and $P_{r}$ is the fracture reopening pressure.

162 These critical pressures are directly related to the rock effective stress state. A basic a

163 method to relate these parameters is detailed in ASTM D4645 (2008). 
165 objective was to create a new hydraulically conductive fracture in the rock specimen.

166 This event typically coincided with real-time AE which could be located and monitored

167 to estimate fracture length. A secondary objective was to contain the final hydraulic

168 fracture extents within the confines of the rock specimens to minimize boundary effects.

169 Interception of the fracture with the boundary of the specimen causes significantly

170 increased leak-off due to a lack of applied pore pressure at the boundary, a situation

171 comparable to intercepting a large permeable fault at the field-scale. Fracture growth was

172 halted by ceasing fluid injection when $\mathrm{AE}$ associated with fracture propagation

173 approached the boundary of the specimen. Injection fluid flow reversal was an additional

174 method used limit fracture length if significant fracture growth continued after ceasing

175 injection. Heterogeneity and pre-existing discontinuities in granite specimens complicate

176 this procedure and add uncertainty to estimations of the created fracture extents.

177 MIF stimulation was performed using a method where the pumps supplied a high

178 pressure impulse to the injection well. The procedure involved pressurizing the pumps

179 while the valve at the wellhead was closed to isolate the pump fluids from the well fluids.

180 The well was filled with liquid and maintained at hydrostatic pressures during pump

181 pressurization. An impulse was generated by opening the wellhead valve and permitting

182 the high pressure pump fluid to contact the well fluid. The treatment was performed with

183 the accumulator temporarily removed from the hydraulic system to reduce compliance

184 and consequentially reduce injected fluid volumes as estimated by Eq. 1. Additional

185 details on this treatment method and its motivations are discussed in Frash et al. (2013b). 


\subsection{Well Injectivity and Productivity Testing}

Constant pressure $(\mathrm{CP})$, constant flow rate $(\mathrm{CF})$, stepped constant pressure (SCP)

188 and stepped constant flow rate (SCF) injection tests were used to quantify well injectivity

189 and productivity for EGS reservoir characterization. Flow rate and pressure control were

190 provided by the dual syringe pump hydraulic system. A series of repeated CP and SCP

191 tests were executed before and after hydraulic stimulations to characterize well flow and

192 changes caused by stimulations. An example plot of SCP data is provided in Fig. 5 with a

193 single injection step highlighted. Typical step durations programmatically controlled with

19415 min or 30 min durations. Longer durations applied when thermal stability was desired.

195 Pseudo-steady flow rates and pressures were estimated from the final $30 \%$ of data for

196 each step. The pseudo-steady data was compiled into summarizing plots, such as shown

197 in Fig. 6, to aid comparison of multiple SCP tests. Inspection of the pseudo-steady data

198 also provides information about hysteresis and repeatability for each SCP test.

199 Comparison of analyzed data between SCP tests provides insight regarding changes in

200 reservoir flow behavior such as enhancement of well injectivity and the permanence of 201 any enhancement.

202 2.6. Hydraulic Compliance Correction

203 Correction for hydraulic compliance was implemented using calibrated linear204 correlations between well pressure and pumped fluid-volume:

206 where $V_{\text {stored }}$ is the volume of fluid stored in the hydraulic system due to elastic expansion 207 of tubing and other wetted components as caused by pressurization (compliance), $m$ is a 208 calibrated compliance coefficient and $P_{\text {well }}$ is the well pressure. The compliance 
209 coefficient was estimated from the maximum slope of the pressurization interval

210 preceding hydraulic fracture initiation. Corrections for leakage were also applied to

211 improve estimation of $m$ with reference to pre-stimulation injection rates measured

212 during constant pressure injection at $2 \mathrm{MPa}$, a value significantly below the expected

213 hydraulic fracturing pressure of at least $7.5 \pm 1.8 \mathrm{MPa}$ for the granite (Haimson and

214 Fairhurst, 1967).

\section{3. EGS Simulation Results}

216 The two granite specimens used for EGS simulation were given reference names

217 of G01-90 and G01-93. A binary well layout was used for G01-90 and a triplet well

218 layout was used for G01-93. The two specimens were subjected to differing reservoir

219 conditions with G01-93 maintained at a higher temperature. G01-90 was hydraulically

220 fractured with oil injection in multiple stages while G01-93 was fractured with oil and

221 proppant slurry injection. Geothermal fluid production was successful and fully

222 characterized in both experiments. Individual injection tests are labeled according to test

223 type and sequence for consistent referencing within the discussion of each experiment.

224 3.1. G01-90: Binary Well Test

225 Images of the G01-90 granite specimen prior to testing are shown in Fig. 7. A

226 discontinuous band characterized by a relatively dense concentration of quartz with

227 roughly $20^{\circ}$ dip was visible in the specimen. No persistent discrete fractures were

228 identified prior to testing. Positions of thermocouples, strain gages, and AE sensors

229 placed on the specimen's surfaces are shown in Fig. 7. The granite specimen was heated

230 to $50{ }^{\circ} \mathrm{C}$ and subjected to confinement of $12.5,8.3$, and $4.1 \mathrm{MPa}$ for the vertical $\left(\sigma_{v}, z-\right.$

231 axis), intermediate ( $\sigma_{H}, y$-axis), and minimum principal stresses $\left(\sigma_{h}, x\right.$-axis), respectively. 
232 These conditions represent an idealized $460 \mathrm{~m}$ deep crystalline low-temperature HDR 233 reservoir in an anisotropic stress state.

234 Table 3 provides an overview of the schedule for this test which included four 235 stimulation stages and a series of $\mathrm{CP}, \mathrm{CF}, \mathrm{SCP}$ and $\mathrm{SCF}$ injection tests, lasting 106 days 236 in total. Well drilling, hydraulic stimulations and injection tests were performed with 237 HDR reservoir conditions applied. A temporary interruption to the applied HDR 238 conditions occurred after CF \#5 due power loss caused by a windstorm. Analysis of water 239 injection data collected before and after this event indicated that the temporary loss of

240 HDR conditions had a minimal effect on the results. HDR conditions were applied slowly 241 to reduce risk of thermally induced fracturing.

242 Fluid injection was performed through a centered vertical well with $107 \mathrm{~mm}$ 243 cased depth and $74 \mathrm{~mm}$ open length, giving a total injection well depth of $181 \mathrm{~mm}$ into 244 the specimen. Fluid was captured through an oriented production well drilled after 245 hydraulic fracturing. The initial injection fluid was clean SAE 80 W90 gear oil for 246 conventional hydraulic fracture stimulation and hydraulic fracture re-stimulations. Tap

247 water replaced oil as the injection fluid after hydraulic connectivity between the injection 248 and production wells was confirmed through SCP injection testing.

249 Fig. 8 shows well pressure and injected fluid volume data for each of the four 250 stimulation stages. A constant pumped flow rate of $0.05 \mathrm{~mL} / \mathrm{min}$ was used for the 251 hydraulic fracture and re-fracture stimulation treatments. The upstream pressure for MIF 252 stimulation was set at $65 \mathrm{MPa}$. Injected fluid volume data was corrected for hydraulic 253 compliance following Eq. (1) with compliance coefficients of $5.7 \times 10^{-5} \mathrm{~mL} / \mathrm{kPa}$ for the 254 hydraulic fracture and re-fracture stimulations, and $4.0 \times 10^{-5} \mathrm{~mL} / \mathrm{kPa}$ for the MIF 
255 stimulation. Compliance values differed in value due to change of the hydraulic 256 configuration.

257 The initial hydraulic fracture breakdown was brittle with a peak pressure of 18.0 258 MPa. The peak pressure exceeds the prediction from ASTM D4645 but this was expected 259 due to the small well diameter used relative to the field scale (Haimson and Zhao, 1991).

260 Peak pressures in the re-fracture treatments were more ductile and of lower magnitudes at 26115.4 and $17.4 \mathrm{MPa}$, sequentially. The reduction in peak pressure after the initial hydraulic 262 fracture was anticipated because initial fracture growth is expected to decrease rock 263 tensile strength near the wellbore. The similar magnitude between each of the three peak 264 pressures indicates that fracture toughness was less influential than other effects. 265 Exponential extrapolation was needed to estimate the peak pressure for the MIF treatment 266 at $18.7 \mathrm{MPa}$ because pressure was recorded at only $1 \mathrm{~Hz}$, the maximum rate from the data 267 acquisition system used. Strain data was recorded at $5000 \mathrm{~Hz}$ and aided the interpolation 268 process giving increased accuracy for the impulse arrival time and improved estimation 269 of the pressure profile.

$270 \quad$ AE event source locations acquired during the stimulations are shown in Fig. 9.

271 Data from the initial hydraulic fracture stimulation was used to estimate the hydraulic 272 fracture location as propagating away from the injection well on a plane perpendicular to 273 the $x$-axis, the least principal confining stress axis. Clustering of AE events indicated that 274 the fracture was likely bi-wing with a dominant wing propagating in the $-y$ direction. The 275 re-fracturing treatments were observed to continue propagation of the bi-wing fracture. 276 MIF produced a distinctive large magnitude AE event coincident with the arrival of the 277 pressure impulse. The hypocenter of this event (largest circle) was located at the base of 
278 the injection well casing. Fig. 9 also includes the mapped 3D geometry of the fractures

279 observed from cross-sections cut from the specimen after the conclusion of the test.

280 Correlation between recorded AE events and the fracture location is clearly evident.

281 A production well alignment intersecting the $\mathrm{AE}$ indicated dominant fracture

282 wing was selected and drilled after the initial fracture stage. The surface position of the

283 production well relative to the injection well was $58 \mathrm{~mm}$ in the $-y$ direction and $68 \mathrm{~mm}$ in

284 the $-x$ direction with a declination angle of $60^{\circ}$ from the $x$-axis. This alignment

285 intercepted the hydraulic fracture at approximately $118 \mathrm{~mm}$ depth into the granite

286 specimen and provided a distance of at least $58 \mathrm{~mm}$ ( 5 borehole diameters) between the

287 axes of the injection and production wells.

288 Fig. 10 compiles and compares all CP, CF, SCP and SCF results from G01-90.

289 SCP injection tests were found to produce more repeatable results than SCF. Injection

290 flow rates were observed to diminish with time during each step and with total injection

291 time but did not exhibit simple asymptotic behavior. Similar fracture flow degradation

292 behavior has been observed in previous work regarding proppant pack conductivity

293 testing (API RP61, 1989). Typical hysteresis in SCP tests indicated higher injection rates

294 associated with decreasing pressure steps than with increasing steps. Overlap of results

295 between consecutive SCP tests shows non-permanence of the hysteresis effects and time-

296 dependent decreases to injectivity (Frash et al., 2013a). Low levels of AE activity

297 indicated negligible new fracture growth during SCP and SCF injections. Significant and

298 permanent increases to injectivity were observed after each hydraulic stimulation, with

299 the highest level of stimulation achieved by MIF. Oil injection data is highlighted to

300 distinguish the effects of viscosity from those of stimulations. 
302 performed. Fig. 11 shows the production rate from the reservoir as a function of injection

303 rate using data from SCF tests. A maximum ratio of fluid production rate to injection rate

304 of $18 \%$ was measured at a water injection rate of $0.5 \mathrm{~mL} / \mathrm{min}$. Higher injection rates

305 resulted in a larger percentage of injected fluid leak-off into the simulated EGS reservoir.

306 Fluid leak-off was expected to be dominated by flow through the fracture breakthrough at

307 the surface of the granite specimen but also included minor flow through the granite

308 matrix as evident from staining observed proximal to the hydraulic fracture. Similar

309 behavior can be expected at the field-scale when hydraulic fractures intersect natural

310 permeable fracture networks. Likely consequences of high fluid loss include faster

311 cooling of the reservoir and increased required pumping power (parasitic energy loss). It

312 is possible that fluid loss can also contribute to induced seismicity but additional research

313 is necessary to fully understand this phenomenon. When leak-off is significant it is

314 expected that an optimal injection rate to production rate ratio ought to exist. An

315 optimized injection scheme could potentially be achieved by balancing injection rates

316 with production rates.

317 Temperatures, pressures, and flow rates measured during SCF tests were used to

318 estimate fluid enthalpy and energy transfer rates through elements of the simulated EGS

319 reservoir (Fig. 12). Energy transfer rates were estimated as enthalpy change multiplied by

320 flow rate through each reported interval. Leak-off fluid temperature was assumed to

321 equilibrate with the average boundary temperature of the granite specimen at the local

322 atmospheric pressure of $83 \pm 1 \mathrm{kPa}$ at the $1760 \mathrm{~m}(5780 \mathrm{ft})$ elevation of the test site

323 (NOAA, 2014). Note the boiling temperature of water at $83 \mathrm{kPa}$ is approximately $94{ }^{\circ} \mathrm{C}$ 
324 (Borgnakke and Sonntag, 2009). Leak-off flow rate was estimated as the difference

325 between the measured rates of injection and production. The results in Fig. 12 show that

326 most fluid heating occurred through conduction of heat through the injection well casing.

327 Sufficient flow velocities were not achieved to counteract this dominant heat flow

328 pathway due to the low hydraulic conductivity of the stimulated fractures and the high

329 thermal conductivity of both the steel and the granite.

330 Flow from the production well was observed to be non-steady with fluctuating

331 temperatures. The pressure in the production well was $31.5 \pm 2.0 \mathrm{kPa}$ and the nearby rock

332 temperature was stable at $50 \pm 3{ }^{\circ} \mathrm{C}$. Steam stables (e.g. Borgnakke and Sonntag, 2009)

333 show that this state is near the boiling point for water so mixed-phase flow was induced

334 when vacuum was applied to pump fluid from the production well. The steam quality

335 (mass fraction of gas to liquid) of the produced fluid was not measured for this

336 experiment so the bottom-well enthalpy of the produced fluid could not be accurately

337 determined. An estimate of the produced fluid enthalpy was calculated using the

338 measured absolute pressure of $31.5 \mathrm{kPa}$ and temperature measurements from the center of

339 the specimen's top face ( $x=150 \mathrm{~mm}, y=150 \mathrm{~mm}, z=300 \mathrm{~mm})$.

340 Fig. 13 shows a cross-section cut from the granite specimen at $123 \mathrm{~mm}$ depth

341 after injection testing was completed. Two bi-wing fractures were observed in the cross-

342 sections, four fracture wings in total. One wing of the dominant bi-wing fracture

343 propagated to the boundary of the specimen in the $+y$ direction. A different wing from the

344 secondary bi-wing fracture appeared to propagate directly between the production and

345 injection wells with a twisting curvature becoming roughly parallel with and intersecting

346 both wellbore axes. All four fracture wings propagated perpendicular to the minimum 
347 principal stress axis ( $x$-axis). The production well successfully intercepted wings from

348 both the dominant and secondary fractures. The twisting geometry of the secondary bi-

349 wing fracture suggests that it propagated after the production well was drilled. It is

350 expected that the secondary fractures were created or substantially extended by the MIF

351 treatment as indicated by the significant increase to both injectivity and production shown

352 in Figs. 9 and 10.

353 3.2. G01-93: Triplet Well Test

354 Images of the G01-93 granite specimen prior to testing are shown in Fig. 14. A

355 single band of discontinuous material, characterized by a higher than average quartz

356 concentration, was observed dipping at a $70^{\circ}$ angle, striking at $20^{\circ}$ from the $x$-axis, and

357 passing near the center of the specimen. No other large or persistent discontinuities were

358 observed from the surfaces of the specimen. Thin concrete filler with a thickness of $3 \mathrm{~mm}$

359 or less was applied to the specimen's faces to improve surface flatness for load

360 application with the flat jack and steel platen assemblies. The filler improved uniformity

361 of the applied true-triaxial stresses and provided protection for sensors embedded in the

362 surfaces of the granite specimen. Positions of installed thermocouples and AE sensors are

363 shown in Fig. 14. No strain gages were installed for this experiment. The specimen was

364 heated to $80{ }^{\circ} \mathrm{C}$ and subjected to confinement stresses of 13.0, 8.0, and 4.0 MPa for the

365 vertical $\left(\sigma_{\mathrm{v}}, z\right.$-axis), intermediate $\left(\sigma_{\mathrm{H}}, y\right.$-axis), and minimum principal stresses $\left(\sigma_{\mathrm{h}}, x\right.$-axis $)$, 366 respectively.

367 Table 4 provides an overview of the fluid injection schedule for this test which 368 included one hydraulic fracture stimulation stage and a series of $\mathrm{CP}, \mathrm{CF}, \mathrm{SCP}$ and SCF 369 injection tests, lasting 28 days in total. Reservoir conditions were maintained throughout 
370 with 24 hour monitoring. Hydraulic fracturing was performed using SAE 80 W90 oil with

371170 to 325 mesh (0.045 to $0.090 \mathrm{~mm}$ nominal diameter) Ballotini ${ }^{\circledR}$ glass beads added at a

372 loosely packed (gravity settled) concentration to serve as proppant. Two production wells

373 were drilled after fracturing using AE event locations for guidance to create a triplet EGS

374 well layout. The initial oil and proppant slurry was purged from the hydraulics and well

375 after SCP \#2 and the system was then refilled with tap water for improved injectivity

376 with the lower-viscosity fluid. A heat exchanger was installed on the injection wellhead

377 after SCP \#37 to cool injection fluid prior to entry into the true-triaxial cell, increasing

378 the temperature differential between the injected fluid and the model EGS reservoir.

379 The injection well was drilled with a $75^{\circ}$ declination angle from the $-x$ axis along

380 an alignment that passed through the center of the specimen. The respective top surface

381 coordinates were $190 \mathrm{~mm}$ and $150 \mathrm{~mm}$ in the $+x$ and $+y$ directions, respectively. An

382 oriented alignment was chosen with the intent of producing twisting hydraulic fractures.

383 Hydraulic fractures can initiate parallel with the injection well in the near-well region and

384 then transition to an orientation perpendicular to the minimum principal stress $\left(\sigma_{\mathrm{h}}, x\right.$-axis)

385 with propagation (Abass et al., 1996; Hallam and Last, 1991; Valkó and Economides,

386 1995; Weijers et al., 1994).

387 Fig. 15 shows well pressure and injected fluid-volume data for the initial 388 hydraulic fracturing treatment (CF \#1) and additional water injection tests where fracture 389 propagation possibly occurred (CF \#2, CF \#6 and SCF \#5). Hydraulic fracturing was 390 performed with a constant oil injection rate of $0.05 \mathrm{~mL} / \mathrm{min}$ and exhibited multiple 391 breakdown events with a peak pressure at $30.1 \mathrm{MPa}$. A pressure pulse with a magnitude 392 of $30.9 \mathrm{MPa}$ occurred at the end of the hydraulic fracture treatment resulting from closure 
393 of two valves in the hydraulic system. Subsequent SCP tests indicated low injectivity but

394 did confirm fluid flow between the injection and production wells. CF re-stimulations

395 with water injection were performed in an attempt to increase hydraulic conductivity

396 between the wells. These re-stimulations used injection rates of $0.05,0.10,0.20,0.40$,

397 and $0.80 \mathrm{~mL} / \mathrm{min}$, sequentially. Well pressure instability was observed during the first re-

398 stimulation ( $\mathrm{CF} \# 2$ ), but associated AE activity was low and no permanent increase to

399 injectivity was measured by subsequent SCP tests. Injection pressures in subsequent re-

400 stimulations were stable, as with CF \#6, and also exhibited low AE activity and

401 negligible increases to injectivity.

402 Fig. 16 shows the complied SCP test data where the injectivity as a function of 403 pressure was observed to be consistent despite the water re-stimulations attempts. There 404 is a slight change in the profile of the SCP results after SCF \#5 but no net increase to 405 injectivity. These observations led to the implementation of high pressure SCP tests with 406 a maximum pressure of 18.0 MPa instead of 8.0 MPa. Also, high flow rate SCF tests 407 were implemented with peak flow rates up to $6.40 \mathrm{~mL} / \mathrm{min}$. AE activity remained low 408 through the modified SCP and SCF injection tests but higher production rates and larger 409 temperature differentials were achieved for heat transfer study.

410 An unexpected pressure response was observed during high-rate SCF testing 411 where increased injection rates were associated with lower injection pressures but 412 minimal new fracture stimulation. This result suggests a transitional flow condition 413 exhibiting an apparent inverse relationship between injection pressure and flow rate. One 414 possible explanation for this result is a transition from laminar to turbulent flow along at 415 least a portion of the flow path once the flow rate exceeds a critical value. It is also 
416 possible that this phenomenon is a consequence of thermal flow effects. Two-phase flow

417 effects were developed when vacuum pumping the production well induced boiling. Note

418 that the apparent inverse pressure-flow phenomenon was observed both with and without

419 vacuum pumped production. Future modeling efforts could offer additional insight on

420 this phenomenon but this work has not yet been attempted.

421 AE event locations from the initial hydraulic fracture stimulation, shown in Fig.

42217 (CF \#1), were used to select fracture-intercepting production well alignments. A

423 significant amount of $\mathrm{AE}$ activity was observed throughout the stimulation and an

424 activity spike was coincident with the pressure breakdown event. Breakdown associated

425 events (red) were plotted separately from other events (green). Breakdown events were

426 clustered indicating a created fracture with an orientation perpendicular to the minimum

427 principal stress ( $x$-axis). Other events seemed to be clustered near the quartz-rich

428 discontinuity band identified in the specimen prior to testing. The alignments of these two

429 groups of events likely suggested a shear stimulated zone and a tensile hydraulic

430 fractured zone, highlighted in Fig. 17. Event locations throughout all injections tended to

431 follow the same trend as the initial hydraulic fracture stimulation. Inspection of the post-

432 test cross-sections identified a fracture plane co-located with the breakdown associated

433 AE events but no prominent fractures were found in the shear zone.

434 The first production well was drilled into the tensile zone and the second was

435 drilled into the shear zone, as shown in Fig. 17, enabling a comparison of production

436 rates between the two. Production Well \#1 was drilled at $x=206 \mathrm{~mm}$ and $y=193 \mathrm{~mm}$

437 top surface coordinates to a depth of $120 \mathrm{~mm}$ with a dip of $60^{\circ}$ from the $-x$-axis. This

438 alignment intercepted the mid-plane of the breakdown event $\mathrm{AE}$ cluster at an 
439 approximate depth of $100 \mathrm{~mm}$. Production Well \#2 was drilled at top $x=45 \mathrm{~mm}$ and $y=$

$440174 \mathrm{~mm}$ top surface coordinates to a depth of $162 \mathrm{~mm}$ along an azimuth of $315^{\circ}$ from the

$441 x$-axis with a dip of $60^{\circ}$. This alignment intercepted the mid-plane of the other AE event

442 cluster at an approximate depth of $150 \mathrm{~mm}$. Production was ultimately successful only

443 from Production Well \#1 which was confirmed to intersect a prominent fracture by post-

444 test cross-sections.

445 Fig. 18 shows production rate as a function of injection rate using data from SCF

446 \#3 and SCF \#5. Production rates were measurable with vacuum pumping at most

447 injection rates. Passive artesian production was successful only at high rates of injection.

448 No fluid was ultimately produced from Production Well \#2 so vacuum pumping was only

449 installed in Production Well \#1. A maximum fluid production rate to injection rate ratio

450 of $34 \%$ was measured at a water injection rate of $2.20 \mathrm{~mL} / \mathrm{min}$. This fluid recovery ratio

451 decreased at lower injection rates and when the production well was maintained at

452 artesian pressures rather than vacuum. It is expected that the lower net fracture pressures

453 associated with vacuum pumping reduced the leak-off pressure gradient and enabled

454 higher fluid recovery ratios. Higher in-situ pore pressures and in-well artificial lift

455 technologies at the field-scale can be expected to mitigate some issues with fluid leak-off

456 and vacuum induced boiling but balancing is still important to optimize production and 457 injection rates.

458 Bottom-well temperatures in Production Well \#1 were observed to be unstable

459 when vacuum pumping with values ranging from 48 to $80{ }^{\circ} \mathrm{C}$. The absolute pressure in 460 Production Well \#1 during vacuum pumping was measured at $31.5 \pm 2.0 \mathrm{kPa}$. This low 461 pressure and the nearby injection well temperature of $76 \pm 3{ }^{\circ} \mathrm{C}$ indicate that boiling 
462 (mixed-phase flow) was likely the cause of the observed production well's temperature

463 variance (Borgnakke and Sonntag, 2009). The enthalpy of the produced fluid could not

464 be directly determined in this condition because the steam quality was unknown.

465 Therefore an approximation for the enthalpy of the produced fluid was obtained using an

466 absolute pressure of $31.5 \pm 2.0 \mathrm{kPa}$ and the temperature recorded in Production Well \#2

467 when vacuum pumping was applied.

$468 \quad$ Fig. 19 shows the estimated energy transfer rates to and from the injected fluid

469 through selected flow intervals. Fluid production rates for SCF \#5, in which vacuum

470 pumping was not applied, were estimated by linear interpolation between zero and

471 measured rates associated with injection at $6.4 \mathrm{~mL} / \mathrm{min}$. Most fluid heating occurred

472 through the injection well and only minimal heating was measured across the fracture

473 flow interval. These results demonstrate the crucial importance of achieving high

474 hydraulic conductivity through the stimulated reservoir such that parasitic energy losses

475 can be reduced and heat transfer from the rock to the circulated fluid can be improved.

476 The results also demonstrate the significant role of steel casing in the well as a heat

477 transfer element. Generally the thermodynamic system was expected to be conduction 478 dominated.

479 A cross-section from G01-93 at $103 \mathrm{~mm}$ depth is shown in Fig. 20. One bi-wing 480 fracture propagated away from the injection well and this fracture was intercepted by 481 Production Well \#1. The fracture extended sub-vertically and parallel with the alignment 482 of the injection well. The fracture length away from the injection well was not extensive 483 enough to produce a twisted fracture surface. Injected blue dye aided in fracture 484 identification but highlighting was still needed for better contrast in the photograph. The 
485 discontinuity collocated with the AE indicated shear zone is highlighted in Fig. 17. No

486 prominent fractures or evidence of fluid penetration were identified in the discontinuity

487 band. The 3D fracture surfaces complied from all cross-sections are shown in Fig. 16.

\section{Discussion}

The two experiments described provide examples of successful model EGS

490 reservoir simulation where hydraulic fractures were created within initially intact HDR

491 specimens, production wells were drilled using AE for guidance, thermal flow data was

492 acquired, and created fracture geometries were measured. The applied reservoir

493 conditions represent shallow dry low-temperature EGS in natural crystalline rock having

494 negligible initial permeability and porosity. Successful reservoir creation depended upon

495 stimulation of hydraulically conductive fractures between a set of injection and

496 production wells. Hydraulic fracturing contained within the bounds of the specimen was

497 attempted but unsuccessful for effective EGS simulation due to poor hydraulic

498 conductivity through the resulting small fractures. General challenges during these

499 experiments included accurately estimating fracture geometry, understanding the effects

500 of natural heterogeneity and discontinuities, and achieving high-enthalpy fluid production

501 at high-rates while minimizing fluid loss and induced seismicity. HDR conditions

502 increased the challenge of EGS thermal fluid production where pore pressures were not

503 applied to resist fluid leak-off. These same challenges exist at the field-scale so the

504 lessons learned from these experiments can offer insight for the design and optimization 505 EGS. 


\section{1. $\quad$ Selecting Well Alignments using AE}

507 Successfully selecting the location of production wells in these experiments

508 depended on accurately estimating the location of stimulated fractures in the rock

509 specimen and intersecting the fractures with the new wells. Data filtering significantly

510 benefitted estimation of fracture locations where poorly-localized and low-magnitude AE

511 events were neglected to improve visualization. This basic filtering was successful for

512 identifying the location of the hydraulic fracture in G01-90 but additional filtering was

513 required for G01-93. Temporal filtering in G01-93 enabled isolation of AE activity along

514 a pre-existing discontinuity from the main tensile hydraulic fracture location. Fluid

515 production from G01-93 was ultimately successful from a well in the tensile hydraulic

516 fractured zone but not from a second well in the pre-existing discontinuity. This result

517 stresses the importance of coupled fluid flow and AE analysis at the field-scale to

518 improve interpretation of stimulation data. Specifically, a parsed analysis of the AE data

519 coincident with pressure breakdown was effective in this laboratory test and a similar

520 benefit can be expected for field-scale experiments. It is important to note that $\mathrm{AE}$

521 analysis for G01-90 and G01-93 was performed without referencing the known applied

522 stress directions to reduce bias.

\section{4.2. Thermal-Fluid-Production Relationships}

524 Thermal fluid flow though G01-90 and G01-93 was observed to be a complex

525 function of geometry, injection pressure, temperatures and flow history. Geometry was

526 the dominant factor controlling fluid flow where fluid more easily passed through

527 fractures than the rock-matrix. SCP and SCF injection tests demonstrated that injectivity

528 decreased but was more constant as a function of injection pressure rather than flow rate. 
529 Pressure controlled injection tended to produce pseudo-steady flow conditions while flow

530 rate control produced unsteady fluctuating pressures and a greater likelihood of additional

531 stimulation. Fluid and rock temperatures had a complex interdependent effect on flow

532 where faster injection of cold fluid was observed to increase hydraulic conductivity

533 through the fractures. Flow history effects were evident through SCP hysteresis where

534 injection at high-rates of flow typically resulted with increased injectivity in subsequent

535 lower-rate injections, even associated AE indicated fracture propagation was negligible.

536 Similar complex multi-physical interactions are also likely at the field-scale.

537 Generally the results from G01-90 and G01-93 suggest that constant flow rate control for

538 injection can be beneficial for improving hydraulic conductivity. These results also show

539 that balancing injection pressures with production well pressures is important for

540 optimizing fluid leak-off and improving production efficiency. This balance is expected

541 to be improved by in-situ pore pressures and saturating fluids in the field which can aid in

542 reduction of leak-off given adequate well pressure and flow rate balancing. Additional

543 experimentation is necessary to fully understand the interactions between these multiple

544 effects to aid in optimization and EGS design.

545 4.3. Effect of Re-stimulations

546 Injectivity and productivity was increased by re-stimulations in both experiments

547 with the most significant improvement observed after MIF \#1 in G01-90. The MIF

548 treatment was performed as a dynamic treatment rather than as a conventional hydraulic

549 fracturing treatment (Frash et al., 2013b). The most significant injectivity increases were

550 observed after treatments which produced high AE activity, indicating new fracture 551 growth. 
A similar benefit from re-stimulations can generally be expected at the field-scale.

553 The lack of negative effects from additional stimulations as observed from these

554 laboratory experiments, aside from increased leak-off, suggests that more stimulation is

555 typically better than less. .

556 4.4. Effect of Proppant

557 The effect of adding proppant to the injection fluid was inconclusive from these

558 experiments. The intent of adding proppant was to improve hydraulic conductivity

559 through the fractures at low injection pressures but the results when comparing G01-90

560 and G01-93 appear to imply the inverse. The short stimulated fracture extents and narrow

561 aperture in G01-93 relative to G01-93 are expected to be a strong factor causing this

562 misleading result. Cross-sections indicated minimal, if any, penetration of proppant into

563 the fractures. The impact of adding proppant at the field-scale is not expected to have the

564 detrimental effect implied by these experiments.

565 4.5. Fracture Geometry and Rock Structure

566 Fracture geometries observed from cross-sections after testing showed a tendency

567 for hydraulic fractures to match the alignments of wellbores that they intersected and

568 fracture growth was also strongly affected by discontinuities and heterogeneities. In G01-

56990 , a secondary bi-wing fracture twisted and matched the alignments of both the injection

570 and production wells which it intersected. In G01-93, the created fracture followed the

571 injection well alignment matching the $75^{\circ}$ dip but otherwise propagated sub-

572 perpendicular to the minimum principal stress axis. These geometries agree with previous

573 studies on the effects of borehole orientation (Behrmann and Elbel, 1991; Weijers at al.,

574 1994; Abass et al., 1996; Warpinski and Teufel, 1987). 
576 observed AE activity during these tests. In G01-90 the sub-horizontal quartz-rich

577 discontinuity was observed to inhibit upward fracture growth, as shown with Figs. 7, 9

578 and 13. In G01-93 the sub-vertical discontinuity was observed to generate significant AE

579 activity without any associated prominent fracture growth, as shown with Figs. 14, 17

580 and 20. These discontinuities appeared to inhibit fracture growth through increased

581 strength (G01-90) or decreased stiffness (G01-93) relative to the surrounding rock. Grain-

582 scale heterogeneity was observed to have a direct effect on fracture roughness and local

583 complexity as evident from the cross-sections. The effects of heterogeneity and

584 discontinuities on fracture geometry are more apparent when compared with fractures in

585 other materials such as concrete and acrylic (Frash, 2014).

586 Rock heterogeneity and discontinuities are abundant in the field with relevant

587 structural features ranging in size from the grain-scale and smaller to the dimensions of

588 massive faults and varying lithologies. Real granite was used in these experiments with

589 known contained discontinuities in an attempt to better mimic the complex structures

590 expected in the field. The result was non-ideal fracture geometry including a mixture of

591 shear and tensile fracture propagation modes as injected fluids followed the path of least-

592 resistance when forced into the rock through a borehole. Fracture propagation behavior

593 through laboratory-scale granite specimens can be expected to obey the same physics as

594 larger scales so similar geometric fracture complexity between the two scales can be

595 expected to occur. Additional study is needed to characterize heterogeneity and

596 distributed discontinuities to bridge the gap between absolute dimension scales in the

597 laboratory, field and models. 


\subsection{Lessons for Future EGS Concepts}

The G01-90 and G01-93 experiments demonstrate the importance of achieving

600 effective stimulations to create successful EGS reservoirs and they also showcase

601 important details and implementation methods which can be beneficial for improving the

602 chance of success in the field. First, these experiments demonstrate that multiple diverse

603 stimulation attempts are generally beneficial. Second, these experiments demonstrate

604 how temporal filtering of AE events coincident with hydraulic pressure breakdown

605 events can aid in isolating hydraulically fractured zones from pre-existing discontinuities.

606 Third, the flow data demonstrates the complex interdependence of fracture geometry,

607 injection pressure, temperatures and flow history on the injectivity and productivity of

608 wells. Fourth, the thermal flow data emphasizes that poor hydraulic conductivity and low

609 flow rates can result with conduction dominated heat transfer in EGS systems. Fifth, the

610 complex fracture geometries demonstrate the difficulty of predicting single-stimulation

611 fracture geometry due to the influence of heterogeneity and discontinuities. Lastly, these

612 two experiments provide examples of successful EGS reservoir creation where AE

613 activity was used to guide production well drilling.

\section{5. Conclusions}

615 Two laboratory experiments were performed to provide examples of EGS

616 production from binary and triplet well layouts in hot dry crystalline rock. Specimens

617 were initially intact granite with injectivity induced entirely through hydraulic fracturing,

618 re-stimulations, and MIF. Successful production was dependent upon intercepting created

619 hydraulic fractures with a production well using AE event locations for guidance.

620 Improved estimation of fracture locations was gained by correlating AE data with the 
621 injection well pressures, specifically pressure breakdown events. Higher fracture fluid

622 pressures relative to the boundary pore pressures resulted in higher leak-off rates. Flow

623 rates were observed to be a direct function of injection pressure but pressure was not

624 observed to be uniquely dependent upon flow rate. Flow was observed to be strongly

625 interdependent with hydraulic geometry, temperature, and flow history. Stepwise

626 decrements to injection pressures were associated with higher injectivity than increments.

627 Heat exchange was observed to be conduction dominated with low flow rate and poor

628 hydraulic conductivity. Fracture geometries were strongly influenced by well alignments,

629 discontinuities and stresses where fractures tended to propagate parallel with the well axis,

630 have propagation inhibited by discontinuities and propagate perpendicular to the

631 minimum principal stress.

\section{Acknowledgements}

633 Financial support provided by the U.S. Department of Energy under DOE Grant No. DE-

634 FE0002760 is gratefully acknowledged. The opinions expressed in this paper are those of

635 the authors and not the DOE.

\section{References}

637 Abass, H.H., Hedayati, S., Meadows, D.L., 1996. Nonplanar Fracture Propagation From 638 a Horizontal Wellbore: Experimental Study. SPE Production \& Facilities 11, 133639 137, http://dx.doi.org/10.2118/24823-PA.

640 API RP 61, 1989. Recommended Practice for Evaluating Short Term Proppant Pack 641 Conductivity, first edition. Washington, DC: API. 
642 ASTM D341-09, 2009. Standard Practice for Viscosity-Temperature Charts for Liquid 643 Petroleum Products. West Conshohocken, Pennsylvania: ASTM International, 644 http://dx.doi.org/ 10.1520/D0341-09.

645 ASTM D4645-08, 2008. Standard Test Method for Determination of In-Situ Stress in 646 Rock Using Hydraulic Fracturing Method. West Conshohocken, Pennsylvania: ASTM International, http://dx.doi.org/10.1520/D4645-04.

648 Behrmann, L.A., Elbel, J.L., 1991. Effect of Perforations on Fracture Initiation. Journal 649 of Petroleum Technology 43, 608-615, http://dx.doi.org/10.2118/20661-PA.

650 Borgnakke, C., Sonntag, R.E., 2009. Fundamentals of Thermodynamics, seventh edition. 651 Hoboken: John Wiley \& Sons.

Tester, J.W., Anderson, B.J., Batchelor, A.S., Blackwell, D.D., DiPippo, R., Drake, E.M., 653 Garnish, J.D., Livesay, B., Moore, M.C., Nochols, K., Petty, S., Toksoez, M.N, 654 Veatch, R.W.J., 2006. The Future of Geothermal Energy: Impact of Enhanced 655 Geothermal Systems (EGS) on the United States in the $21^{\text {st }}$ Century. 656 Massachusetts Institute of Technology, Idaho Falls, ID, USA, pp. 372.

657 de Pater, C.J., Cleary, M.P., Quinn, T.S., Barr, D.T., Johnson, D.E., Weijers, L., 1994. 658 Experimental Verification of Dimensional Analysis for Hydraulic Fracturing. SPE 659 Production \& Facilities 9, 230-238, http://dx.doi.org/10.2118/24994-PA.

660 Frash, L., 2012. Laboratory simulation of an enhanced geothermal reservoir. MS thesis, 661 Colorado School of Mines, Golden, Colorado (October 2012). 
662 Frash, L., 2014. Laboratory-Scale Study of Hydraulic Fracturing in Heterogeneous Media 663 for Enhanced Geothermal Systems and General Well Stimulation. PhD thesis, 664 Colorado School of Mines, Golden, Colorado (October 2014).

665 Frash, L., Gutierrez, M., Hampton, J., 2013a. A Laboratory Investigation of Reversible 666 Permeability Decline Effects during Flow through Stimulated Fracture Networks:

667 Implications for Improved EGS Reservoir Operation Methodologies. In: Paper 668 Presented at Thirty-Eighth Workshop on Geothermal Reservoir Engineering, 1166913 February 2013, Stanford, California, USA.

670 Frash, L., Hampton, J., Gutierrez, M., 2013b. Experimentation with Hydraulic Impulse 671 Stimulation in a Scaled Enhanced Geothermal Systems Reservoir. In: Paper 672

674 GTO, 2014. 2013 Geothermal Technologies Office Annual Report. 675 http://www1.eere.energy.gov/geothermal/pdfs/gto-annual-report2013.pdf $676 \quad$ (downloaded December 2014)

677 Haimson, B., Fairhurst, B., 1967. Initiation and Extension of Hydraulic Fractures in $678 \quad$ Rocks. SPE Journal 7, 310-318.

679 Haimson, B., Zhao, Z., 1991. Effect of borehole size and pressurization rate on hydraulic 680 fracture breakdown pressure. In: Paper Presented at 32nd U.S. Symposium on 681 Rock Mechanics (USRMS), 10-12 July 1991, Norman, Oklahoma, USA. 
682 Hallam, S.D., Last, N.C., 1991. Geometry of Hydraulic Fractures from Modestly 683 Deviated Wellbores. Journal of Petroleum Technology 43, 742-748, 684 http://dx.doi.org/10.2118/20656-PA.

685 Ishida, T., Chen, Q., Mizuta, Y., Roegiers, J.C., 2004. Influence of Fluid Viscosity on the 686 Hydraulic Fracturing Mechanism. Journal of Energy Resources Technology 126, 687 190-200, http://dx.doi.org/10.1115/1.1791651.

688 NOAA, 2014. Daily Archived Barometric Pressure Data. 689 http://www.crh.noaa.gov/bou/awebphp/prevwx.php\#pressure (downloaded 23 690 June 2014).

691 Valkó, P., Economides, M., 1995. Hydraulic Fracture Mechanics. New York: John Wiley $692 \&$ Sons.

693 Valvoline, 2012. Product Information, Valvoline ${ }^{\circledR}$ DuraBlend $^{\circledR}$ Gear Oil. 694 http://www.valvoline.com/pdf/durablend_gear.pdf (downloaded 5 May 2014).

695 Warpinski, N.R., Clark, J.A., Schmidt, R.A., Huddle, C.W., 1982. Laboratory 696 investigation on the effect of in-situ stresses on hydraulic fracture containment. 697 SPE Journal 22, 333-340.

698 Warpinski, N.R., Teufel, L.W., 1987. Influence of geologic discontinuities on hydraulic 699 fracture propagation. Journal of Petroleum Technology 39, 209-220. 
700 Weijers, L., de Pater, C.J., Owens, K.A., Kogsbøll, H.H., 1994. Geometry of Hydraulic

$701 \quad$ Fractures Induced from Horizontal Wellbores. SPE Production \& Facilities 9, 87-

702 92, http://dx.doi.org/10.2118/25049-PA.

703 White, F.M., 2009. Fluid Mechanics, sixth edition. Boston: McGraw-Hill.

704 
706 Table 1

707 Granite material properties.

\begin{tabular}{ll}
\hline Property & Value \\
\hline Uniaxial Compression Strength $(\mathrm{MPa})$ & $152 \pm 19$ \\
Poisson's Ratio & 0.32 \\
Elastic Modulus $(\mathrm{GPa})$ & 56.9 \\
Density $(\mathrm{g} / \mathrm{cm} 3)$ & $2.63 \pm 0.03$ \\
Indirect Tensile Strength $(\mathrm{MPa})$ & $7.5 \pm 1.8$ \\
Thermal Conductivity $\left(\mathrm{W} / \mathrm{m}^{2}\right)$ & $3.14 \pm 0.05$ \\
Volumetric Specific Heat Capacity $\left(\mathrm{kJ} / \mathrm{m}^{3} \cdot \mathrm{K}\right)$ & $2063 \pm 92$ \\
Porosity & $0.008 \pm 0.001$ \\
Permeability $(\mu \mathrm{D})$ & $\leq 1.16$ \\
Shear Wave Velocity $(\mathrm{km} / \mathrm{s})$ & 2.62 \\
Compression Wave Velocity $(\mathrm{km} / \mathrm{s})$ & 4.45 \\
\hline
\end{tabular}

708

709 
Table 2

711 Properties of injected fluids.

\begin{tabular}{llll}
\hline Fluid & Temperature $\left({ }^{\circ} \mathrm{C}\right)$ & Viscosity $(\mathrm{cP})$ & Density $(\mathrm{g} / \mathrm{mL})$ \\
\hline Tap Water & $23^{\circ} \mathrm{C}$ & $9.42 \cdot 10^{-1}$ & 0.998 \\
& $50^{\circ} \mathrm{C}$ & $5.46 \cdot 10^{-1}$ & 0.988 \\
& $80^{\circ} \mathrm{C}$ & $3.54 \cdot 10^{-1}$ & 0.971 \\
80W90 Oil & $23^{\circ} \mathrm{C}$ & $3.23 \cdot 10^{2}$ & 0.887 \\
& $50^{\circ} \mathrm{C}$ & $7.15 \cdot 10^{1}$ & - \\
& $80^{\circ} \mathrm{C}$ & $2.26 \cdot 10^{1}$ & - \\
\hline
\end{tabular}

712

713 


\section{Table 3}

715 G01-90 testing schedule.

\begin{tabular}{|c|c|c|c|}
\hline $\begin{array}{l}\text { General } \\
\text { Stage }\end{array}$ & Fluid & Stage ID & Stage Details \\
\hline $\begin{array}{l}\text { Hydraulic } \\
\text { fracturing }\end{array}$ & $\begin{array}{l}\text { SAE } 80 \text { W90 oil, } \\
68 \mathrm{cP} @ 51^{\circ} \mathrm{C}\end{array}$ & $\begin{array}{l}\text { CP \#1 } \\
\text { CF \#1 } \\
- \\
\text { SCP \#1 }\end{array}$ & $\begin{array}{l}2.0 \mathrm{MPa} \\
0.05 \mathrm{~mL} / \mathrm{min} \\
\text { Drilled production well } \\
2.0 \text { to } 4.0 \mathrm{MPa}\end{array}$ \\
\hline $\begin{array}{l}\text { Re-fracture } \\
\# 1\end{array}$ & $\begin{array}{l}\text { SAE } 80 \text { W90 oil, } \\
68 \mathrm{cP} @ 51^{\circ} \mathrm{C}\end{array}$ & $\begin{array}{l}\text { CF \#2 } \\
\text { CP \#2 } \\
\text { SCP \#2 to \#7 }\end{array}$ & $\begin{array}{l}0.05 \mathrm{~mL} / \mathrm{min} \\
4.0 \mathrm{MPa} \\
2.0 \text { to } 6.0 \mathrm{MPa}\end{array}$ \\
\hline $\begin{array}{l}\text { Re-fracture } \\
\# 2\end{array}$ & $\begin{array}{l}\text { SAE } 80 \text { W90 oil, } \\
68 \mathrm{cP} @ 51^{\circ} \mathrm{C}\end{array}$ & $\begin{array}{l}\text { CF \#3 } \\
\text { SCP \#8 } \\
\text { SCF \#1 } \\
\text { SCF \#2 }\end{array}$ & $\begin{array}{l}0.05 \mathrm{~mL} / \mathrm{min} \\
2.0 \text { to } 6.0 \mathrm{MPa} \\
0.00001 \text { to } 0.003 \mathrm{~mL} / \mathrm{min} \\
0.003 \text { to } 0.03 \mathrm{~mL} / \mathrm{min}\end{array}$ \\
\hline $\begin{array}{l}\text { Water } \\
\text { injection }\end{array}$ & $\begin{array}{l}\text { Water, } \\
0.55 \mathrm{cP} @ 50^{\circ} \mathrm{C}\end{array}$ & $\begin{array}{l}- \\
\mathrm{CF} \# 4 \\
\mathrm{CF} \# 5 \\
- \\
\text { SCF\#3 } \\
\mathrm{CP} \# 3 \\
\mathrm{SCP} \# 9 \\
\mathrm{CP} \# 4 \\
\mathrm{SCP} \# 10 \text { to \#11 } \\
\mathrm{CF} \# 6 \\
\mathrm{CF} \# 7 \\
\mathrm{CP} \# 5 \\
\mathrm{SCP} \# 12 \text { to \#15 }\end{array}$ & $\begin{array}{l}\text { Purged oil from injection well } \\
0.05 \mathrm{~mL} / \mathrm{min} \\
0.10 \mathrm{~mL} / \mathrm{min} \\
\text { Temporary loss of heating and } \\
\text { confinement conditions } \\
0.05 \text { to } 3.0 \mathrm{~mL} / \mathrm{min} \\
2.0 \mathrm{MPa} \\
2.0 \text { to } 6.0 \mathrm{MPa} \\
2.0 \mathrm{MPa} \\
2.0 \text { to } 6.0 \mathrm{MPa} \\
0.05 \mathrm{~mL} / \mathrm{min} \\
0.10 \mathrm{~mL} / \mathrm{min} \\
2.0 \mathrm{MPa} \\
2.0 \text { to } 6.0 \mathrm{MPa}\end{array}$ \\
\hline MIF & $\begin{array}{l}\text { Water, } \\
0.55 \mathrm{cP} @ 50^{\circ} \mathrm{C}\end{array}$ & $\begin{array}{l}\text { MIF \#1 } \\
\text { SCP \#16 to \#17 } \\
\text { CF \#8 } \\
\text { CF \#9 } \\
\text { CF \#10 } \\
\text { CF \#11 } \\
\text { SCP \#18 }\end{array}$ & $\begin{array}{l}65 \mathrm{MPa} \text { impulse stimulation } \\
0.5 \text { to } 7.0 \mathrm{MPa} \\
0.50 \mathrm{~mL} / \mathrm{min} \\
1.00 \mathrm{~mL} / \mathrm{min} \\
3.00 \mathrm{~mL} / \mathrm{min} \\
5.00 \mathrm{~mL} / \mathrm{min} \\
0.5 \text { to } 6.0 \mathrm{MPa}\end{array}$ \\
\hline
\end{tabular}


719 G01-93 testing schedule.

\begin{tabular}{|c|c|c|c|}
\hline $\begin{array}{l}\text { General } \\
\text { Stage }\end{array}$ & Fluid & Stage ID & Stage Details \\
\hline $\begin{array}{l}\text { Hydraulic } \\
\text { fracturing }\end{array}$ & $\begin{array}{l}80 \mathrm{~W} 90 \text { oil } \\
\text { and proppant, } \\
22 \mathrm{cP} @ 80^{\circ} \mathrm{C}\end{array}$ & $\begin{array}{l}\text { CP \#1 } \\
\text { CF \#1 } \\
- \\
\text { SCP \#1 } \\
- \\
\text { SCP \#2 } \\
-\end{array}$ & $\begin{array}{l}2.0 \mathrm{MPa} \\
0.05 \mathrm{~mL} / \mathrm{min} \\
\text { Drilled production well \#1 } \\
2.0 \text { to } 8.0 \mathrm{MPa} \\
\text { Drilled production well \#2 } \\
2.0 \text { to } 8.0 \mathrm{MPa} \\
\text { Purged oil from injection well }\end{array}$ \\
\hline $\begin{array}{l}\text { Water } \\
\text { injection }\end{array}$ & $\begin{array}{l}\text { Water, } \\
0.35 \mathrm{cP} @ 80^{\circ} \mathrm{C}\end{array}$ & $\begin{array}{l}\text { SCP \#3 to \#4 } \\
\text { CF \#2 } \\
\text { SCP \#5 to \#9 } \\
\text { CF \#3 } \\
\text { SCP \#10 to \#13 } \\
\text { CF \#4 } \\
\text { SCP \#14 to \#20 } \\
\text { CF \#5 } \\
\text { SCP \#21 to \#24 } \\
\text { CF \#6 } \\
\text { SCP \#25 to \#26 } \\
\text { SCP \#27 to \#32 } \\
\text { SCF \#1 } \\
\text { SCP \#33 to \#37 } \\
- \\
\text { SCP \#38 to \#40 } \\
\text { SCF \#2 to \#3 } \\
\text { SCP \#41 to \#44 } \\
\text { SCF \#4 } \\
\text { SCP \#45 to \#47 } \\
\text { SCF \#5 } \\
\text { SCP \#48 to \#49 }\end{array}$ & $\begin{array}{l}2.0 \text { to } 8.0 \mathrm{MPa} \\
0.05 \mathrm{~mL} / \mathrm{min} \\
2.0 \text { to } 8.0 \mathrm{MPa} \\
0.10 \mathrm{~mL} / \mathrm{min} \\
2.0 \text { to } 8.0 \mathrm{MPa} \\
0.20 \mathrm{~mL} / \mathrm{min} \\
2.0 \text { to } 8.0 \mathrm{MPa} \\
0.40 \mathrm{~mL} / \mathrm{min} \\
2.0 \text { to } 8.0 \mathrm{MPa} \\
0.80 \mathrm{~mL} / \mathrm{min} \\
2.0 \text { to } 8.0 \mathrm{MPa} \\
2.0 \text { to } 18.0 \mathrm{MPa} \\
0.05 \text { to } 2.20 \mathrm{~mL} / \mathrm{min} \\
2.0 \text { to } 18.0 \mathrm{MPa} \\
\text { Wellhead heat exchanger installed } \\
2.0 \text { to } 18.0 \mathrm{MPa} \\
0.05 \text { to } 2.20 \mathrm{~mL} / \mathrm{min} \\
2.0 \text { to } 18.0 \mathrm{MPa} \\
0.05 \text { to } 2.20 \mathrm{~mL} / \mathrm{min} \\
2.0 \text { to } 18.0 \mathrm{MPa} \\
0.05 \text { to } 6.40 \mathrm{~mL} / \mathrm{min} \\
2.0 \text { to } 18.0 \mathrm{MPa}\end{array}$ \\
\hline
\end{tabular}




\section{$722 \quad$ Figures}

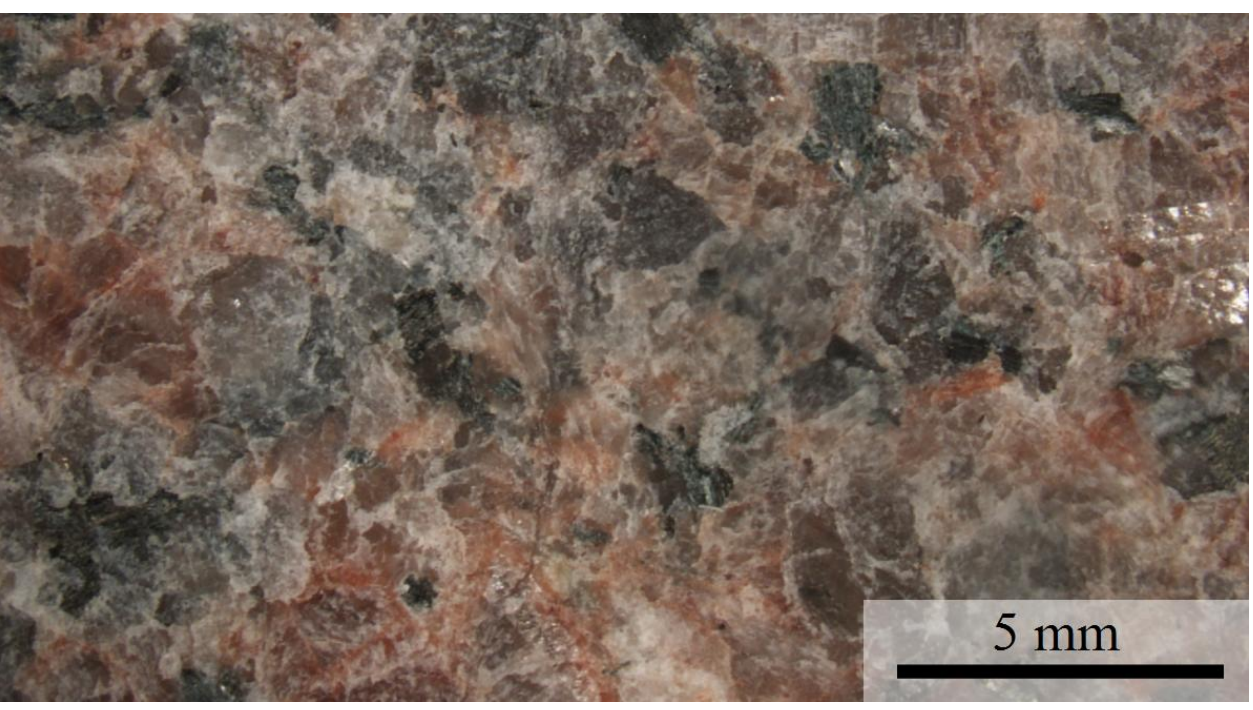

723

Fig. 1. Photomicrograph showing typical grain heterogeneity in the granite. 


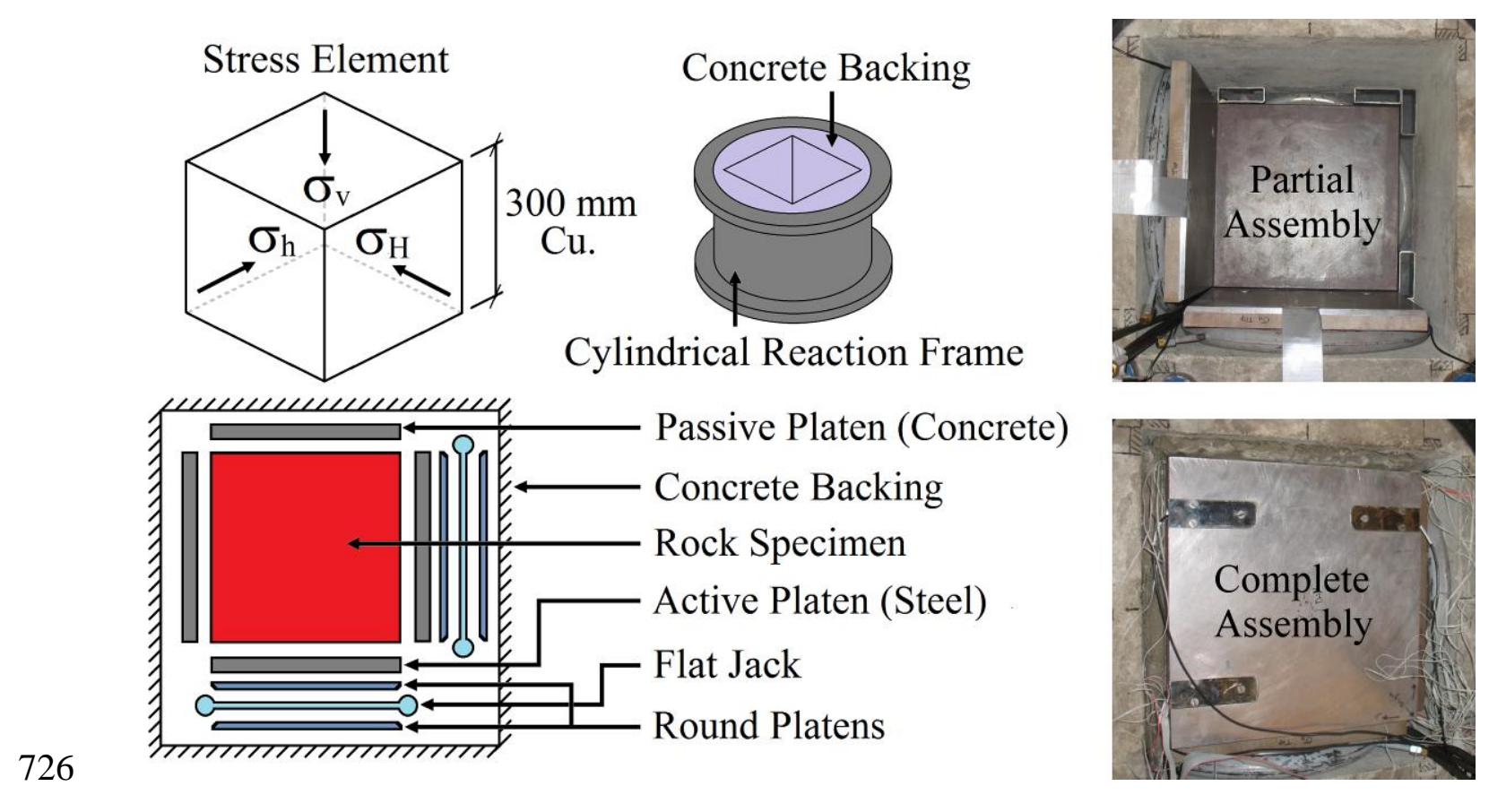

727 Fig. 2. True-triaxial apparatus showing platen and jack assemblies. 


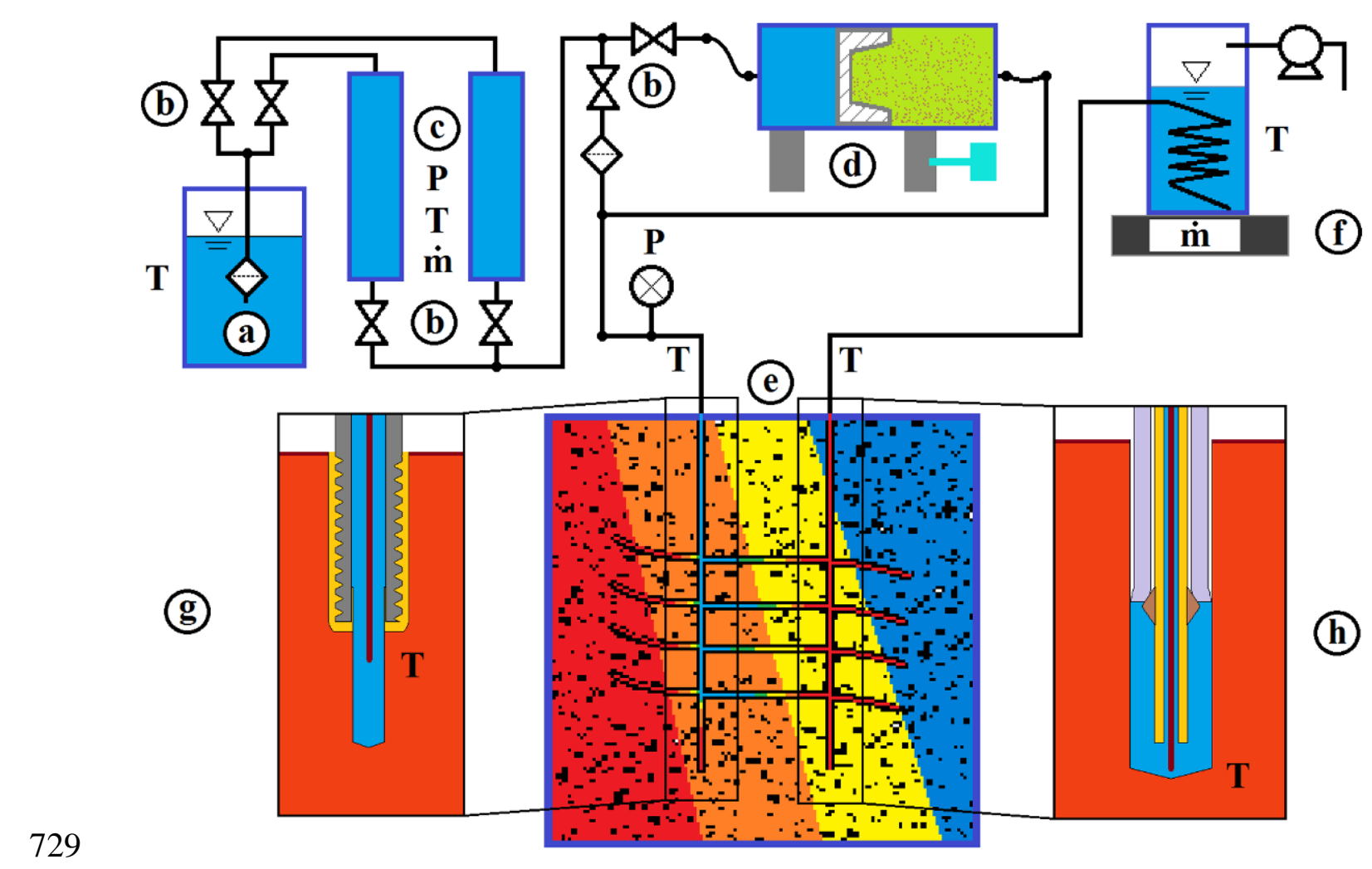

730 Fig. 3. Hydraulics system showing the layout of the pump fluid reservoir (a), valves (b), 731 syringe pumps (c), injection fluid accumulator (d), rock specimen (e), vacuum condenser 732 (f), injection well (g), and production well (h). 


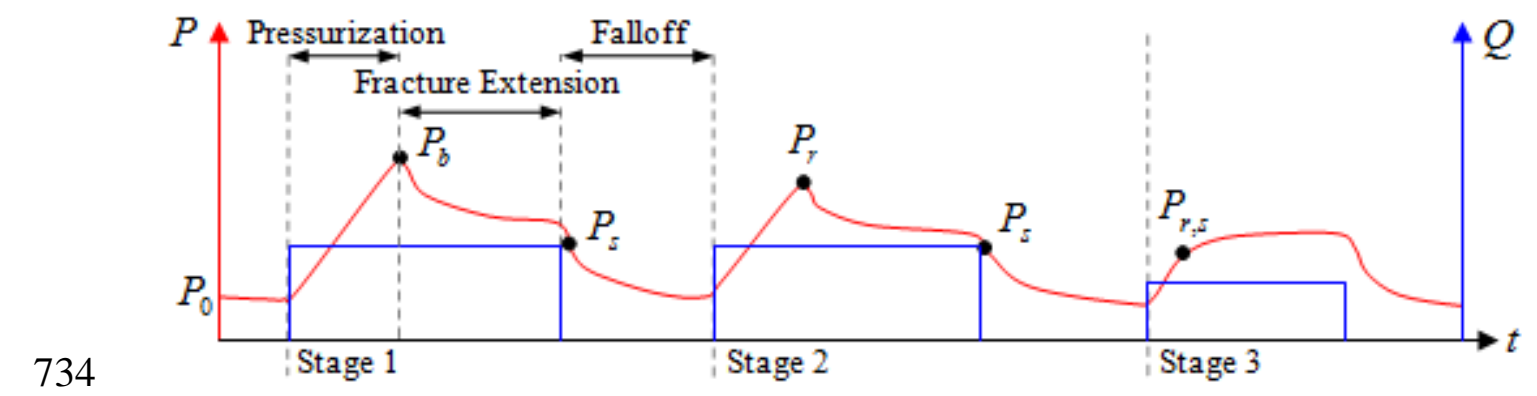

735 Fig. 4. Idealized hydraulic fracture stimulation with three injection stages into one well 736 (adapted from ASTM D4645, 2008). 


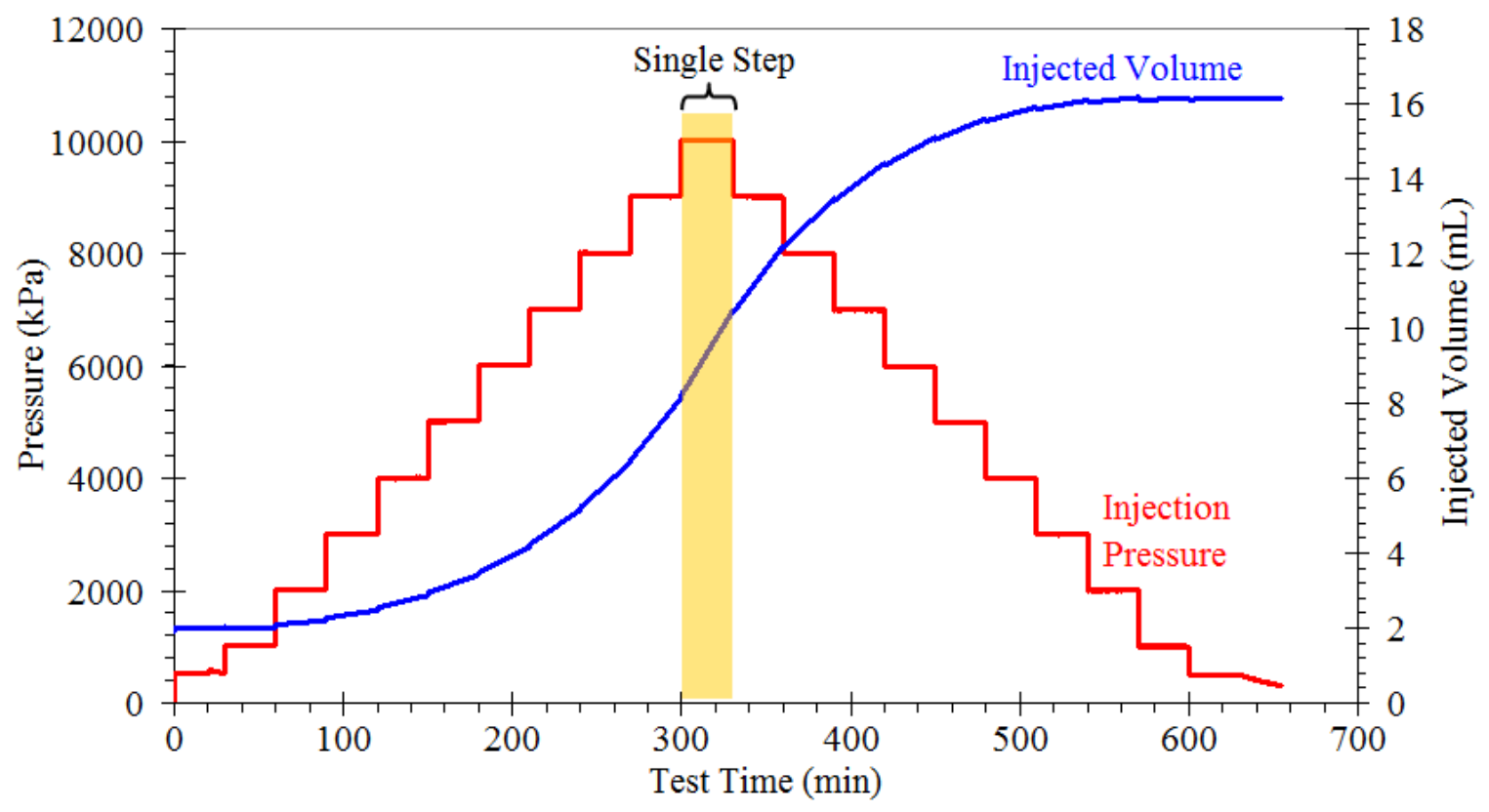

739 Fig. 5. Example raw data from a stepped constant pressure injection test with a single 740 step highlighted (data from G01-90 SCP \#14; Table 3). 


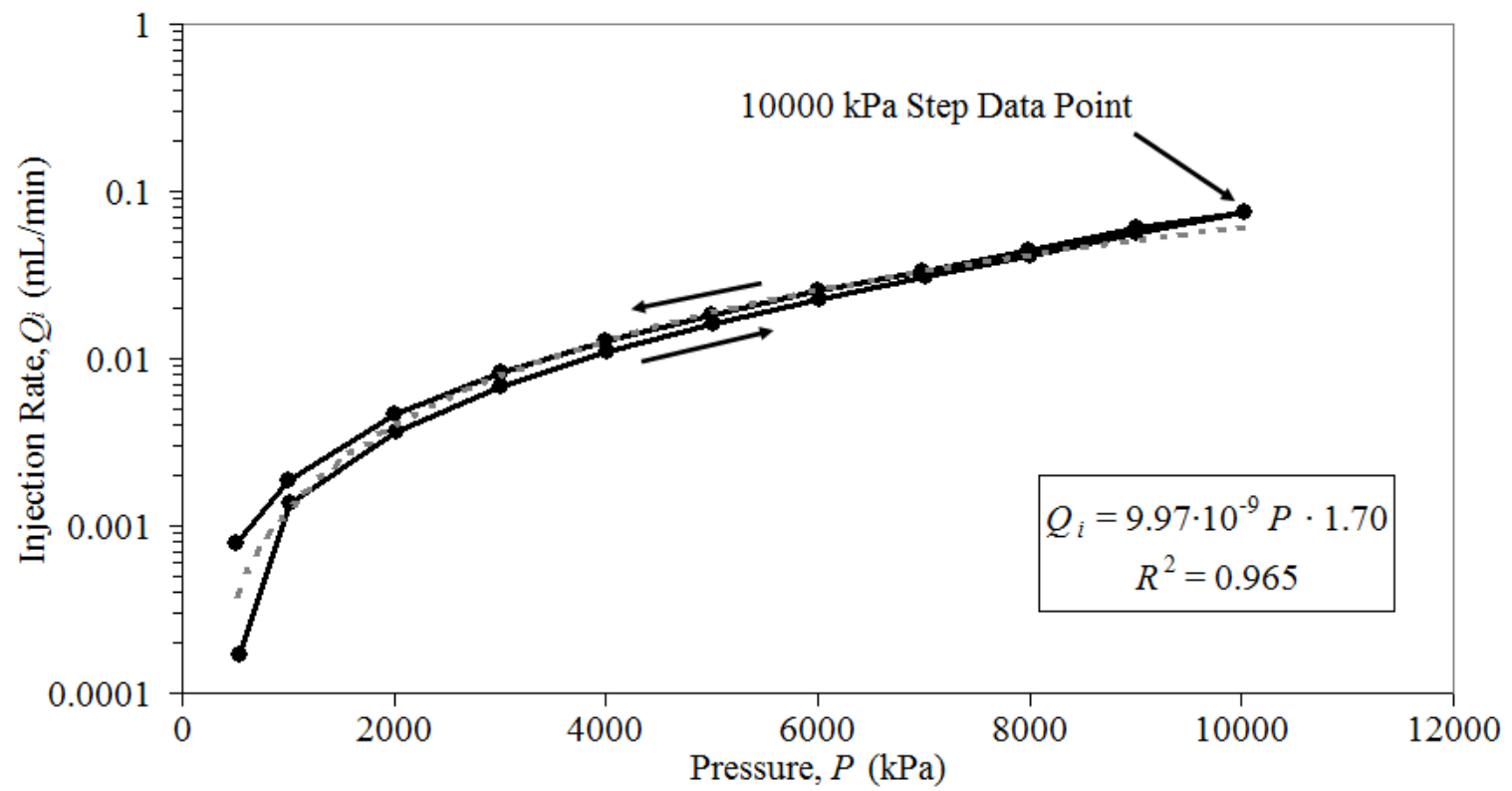

743 Fig. 6. Analyzed pseudo-steady fluid flow data from Fig. 5 using averages of the last $74430 \%$ of data from each constant pressure step. 


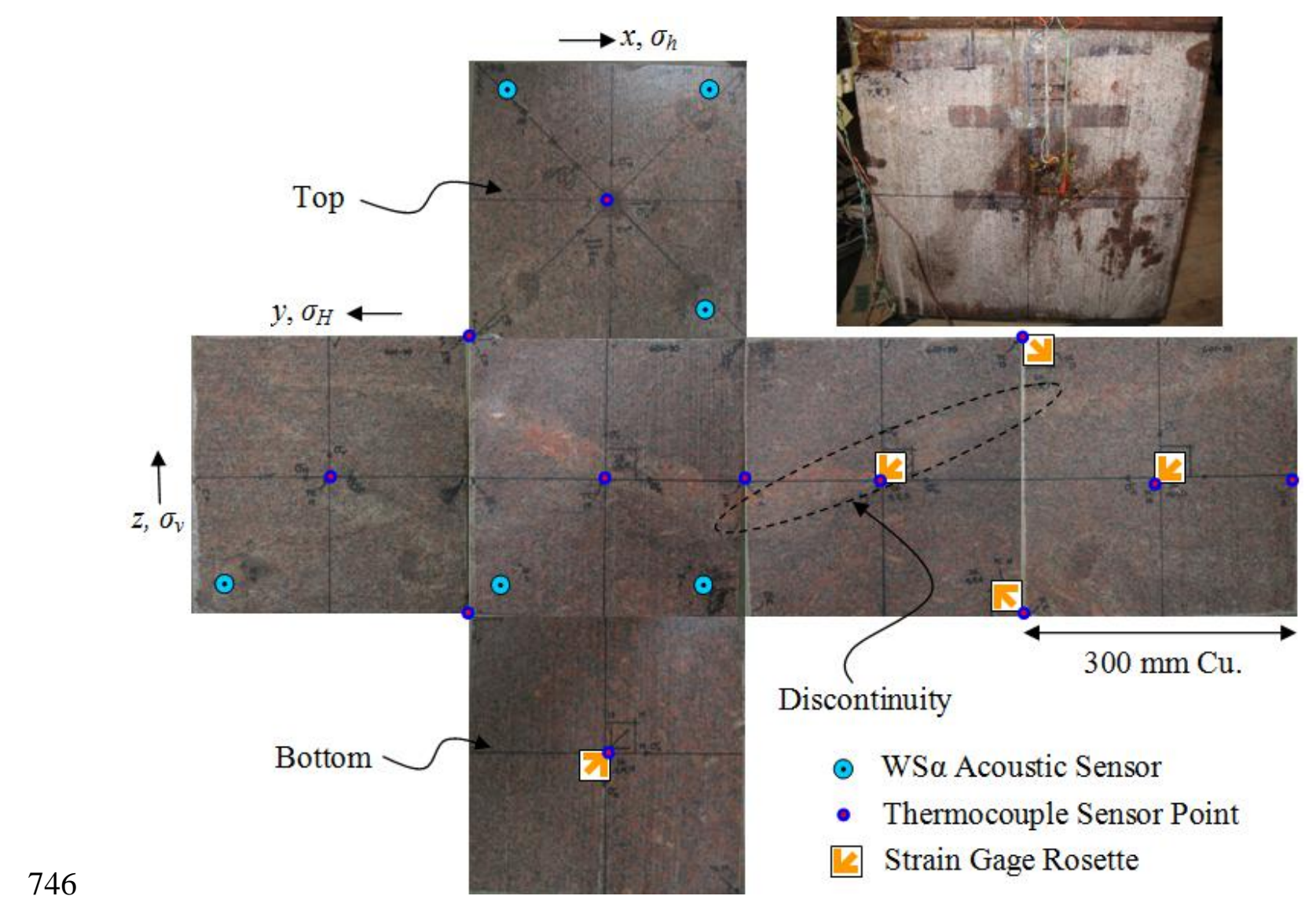

747 Fig. 7. G01-90 granite specimen prior to testing with surface sensor locations and natural 748 discontinuity shown. 

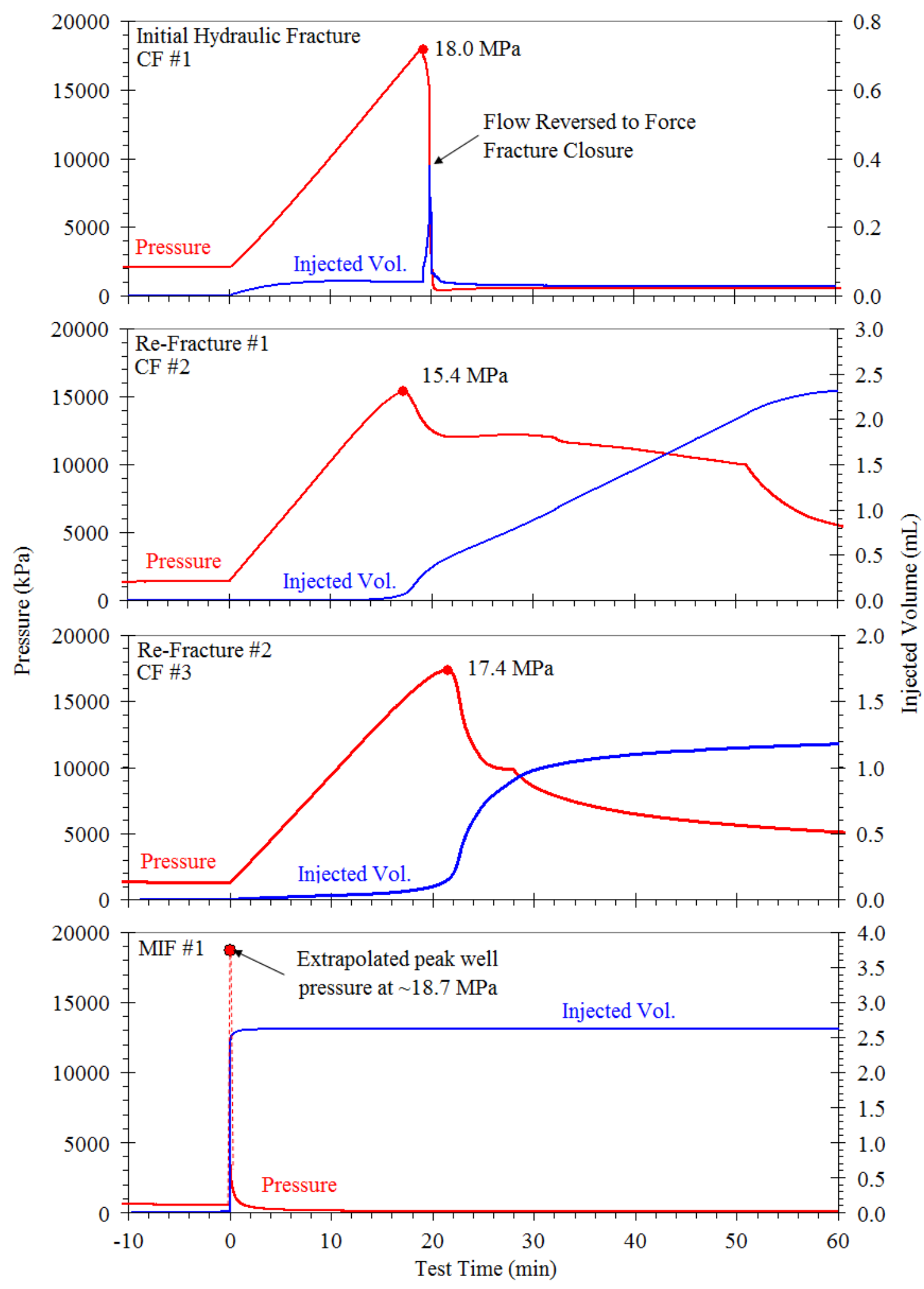

751 Fig. 8. G01-90 stimulation pressures and fluid volumes. 

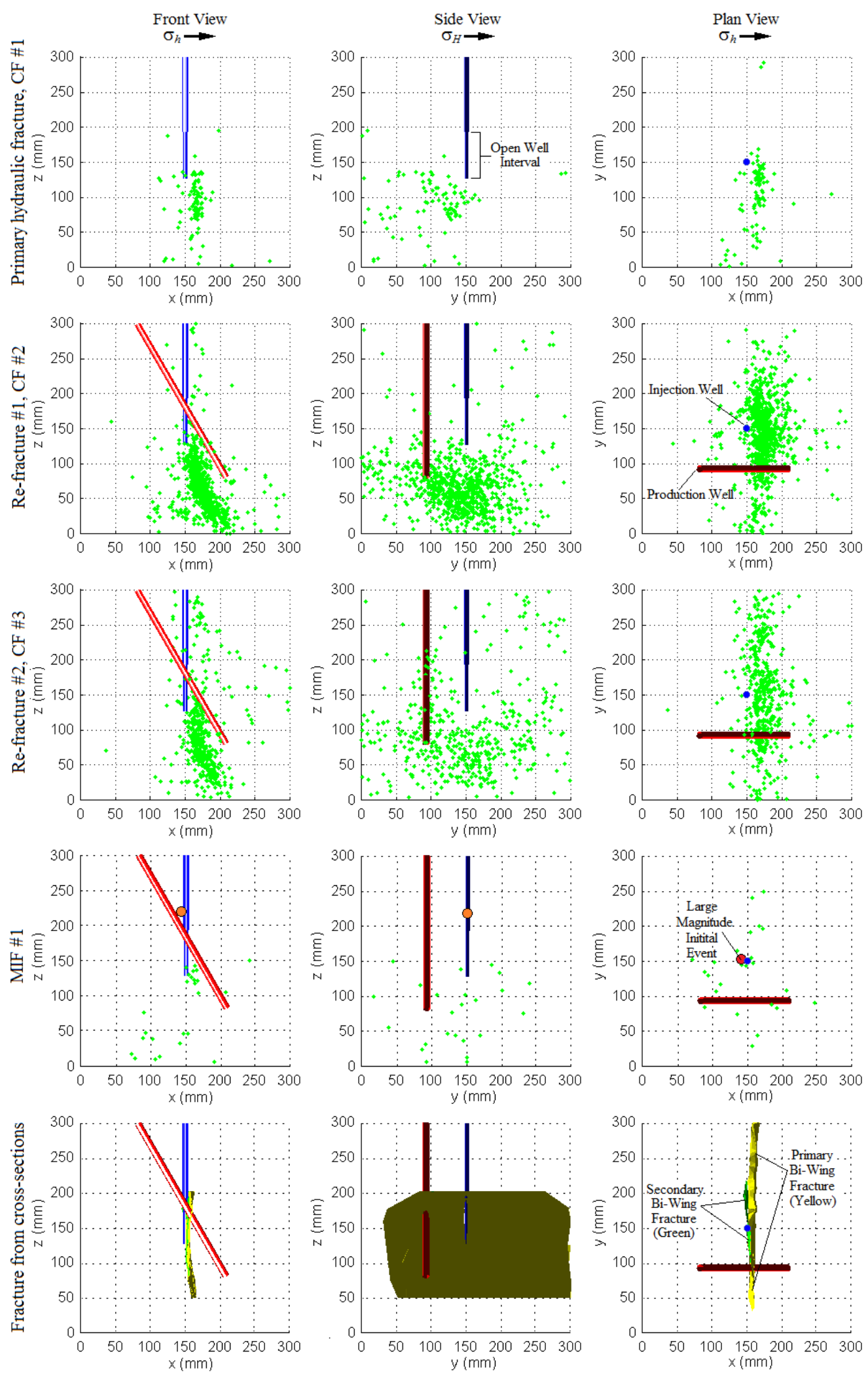

Fig. 9. AE events recorded during G01-90 stimulations and observed final fracture geometry with interpolated intersections between the wells and fractures. 


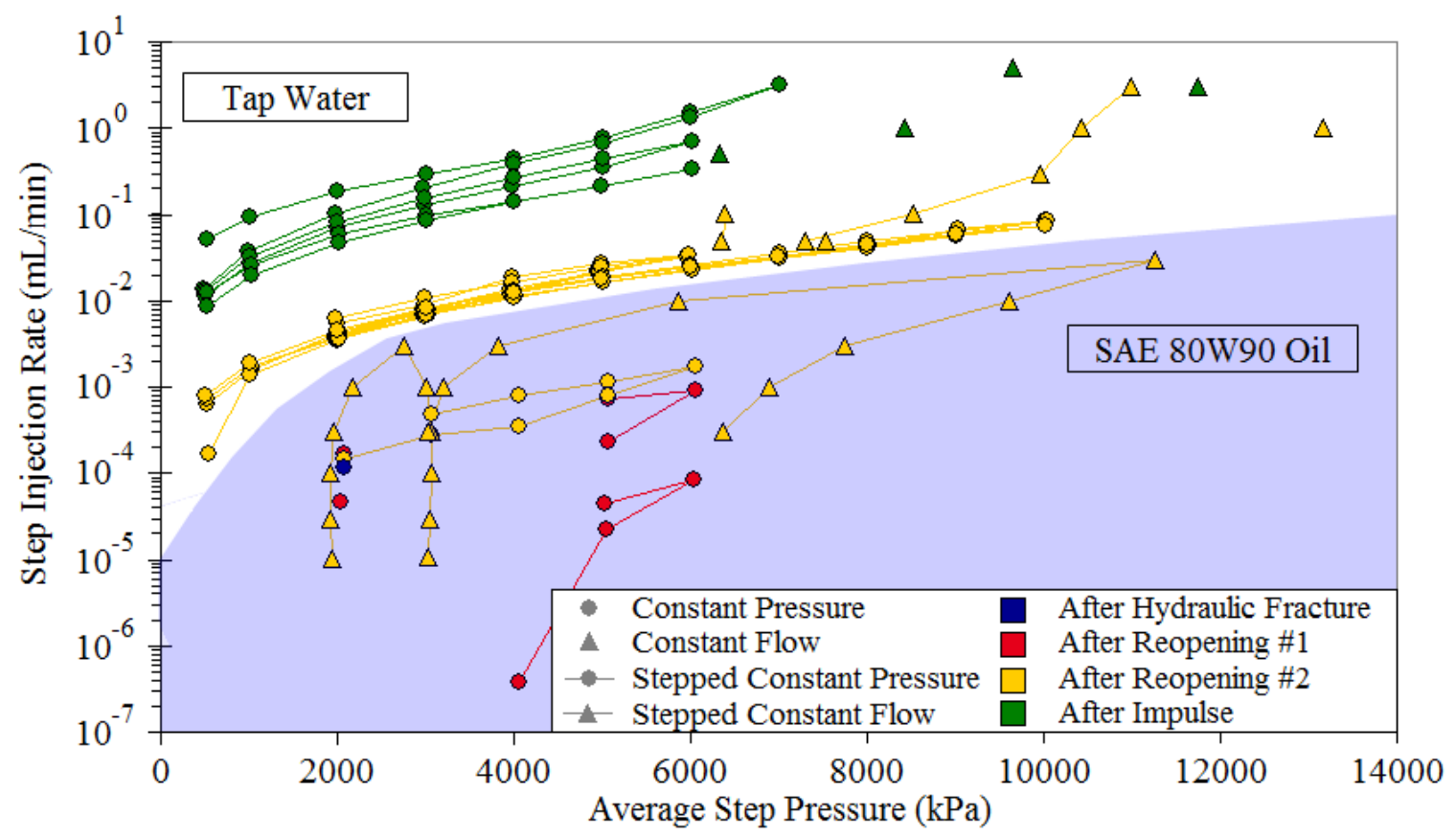

758 Fig. 10. Compiled analyzed data from CP, CF, SCP and SCF injections in G01-90. 


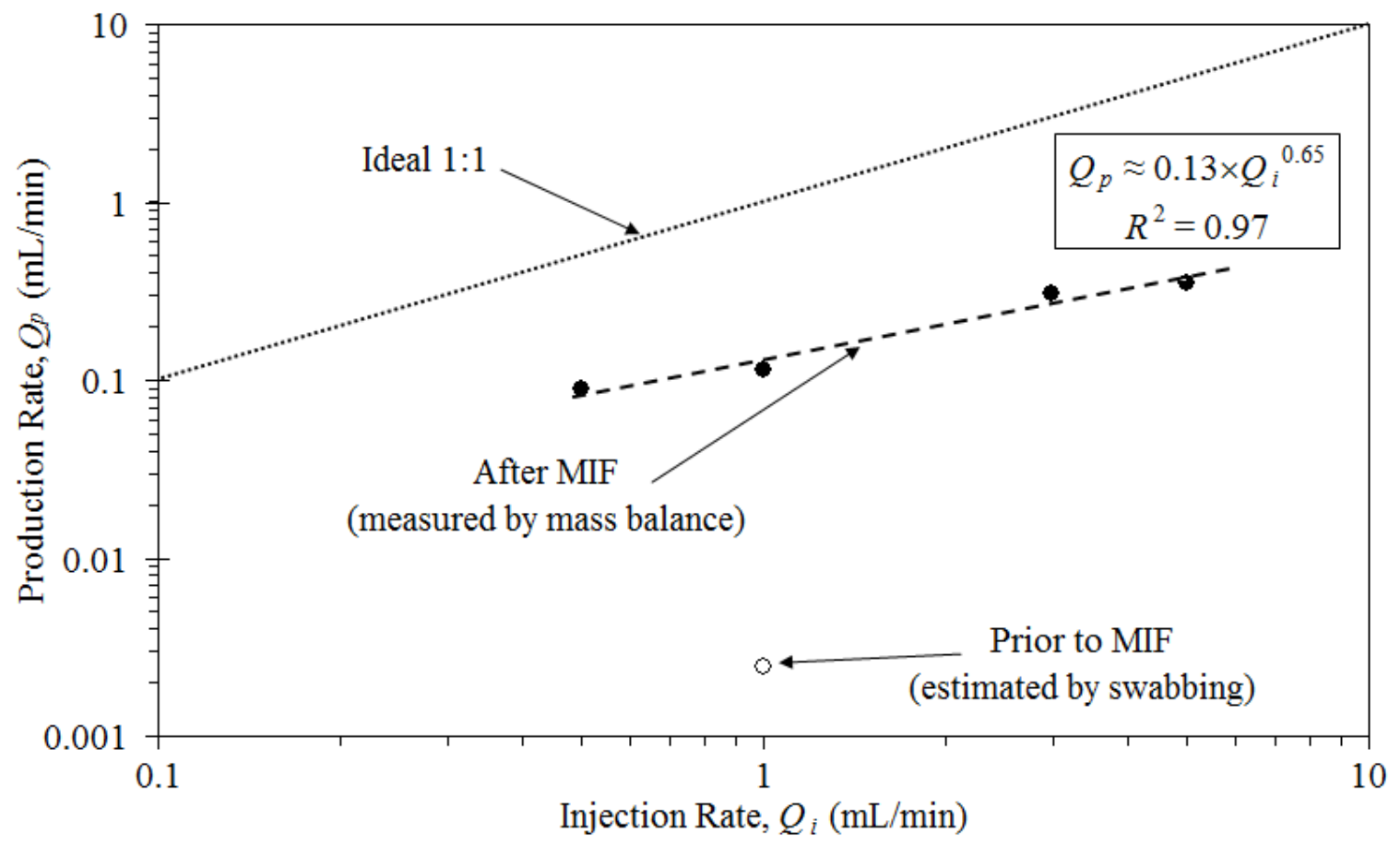

760

761 Fig. 11. G01-90 measured fluid production rates as a function of injection rate. 


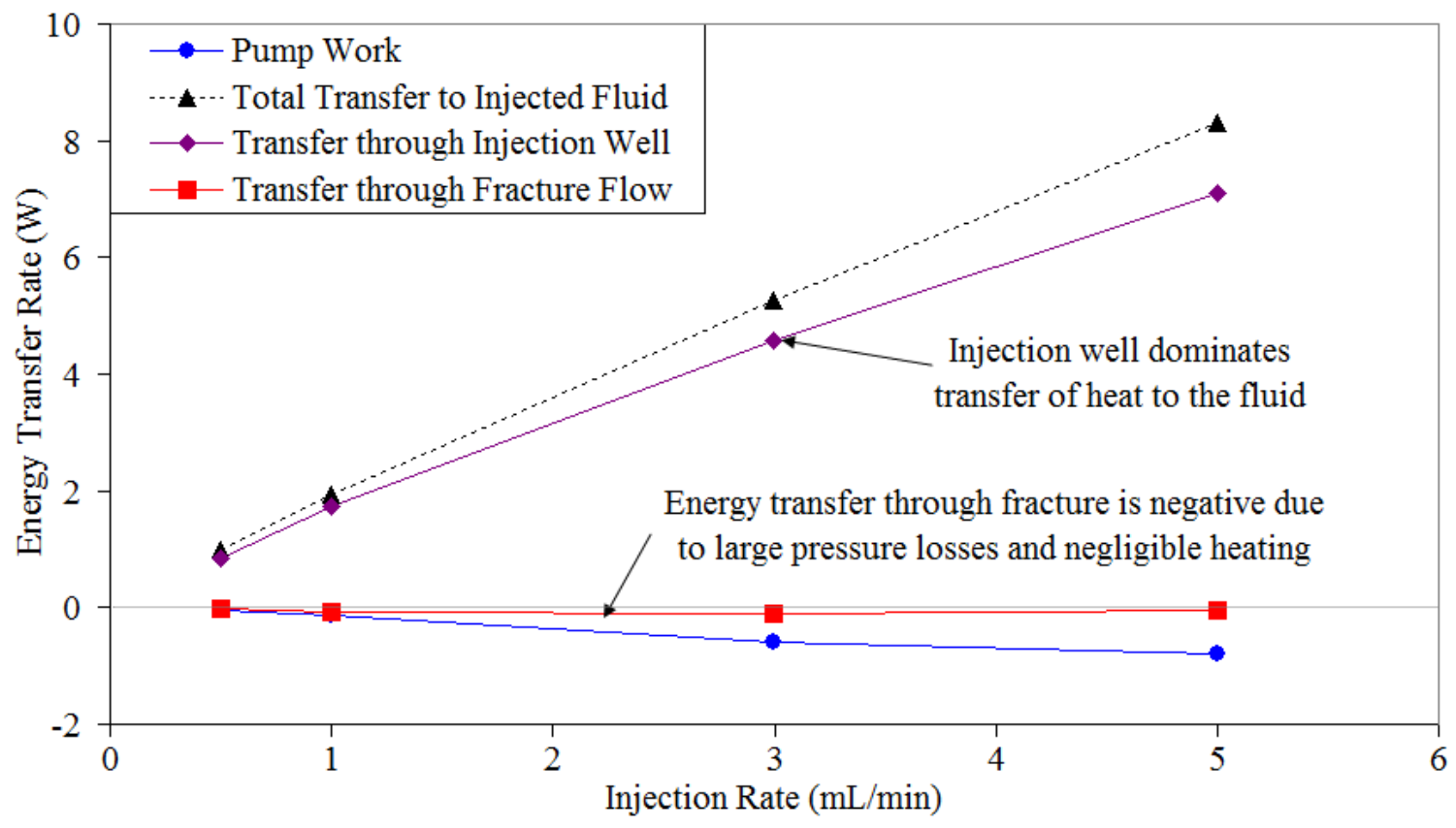

763

764 Fig. 12. Rate of energy transfer through selected zones in G01-90 after MIF. 765 


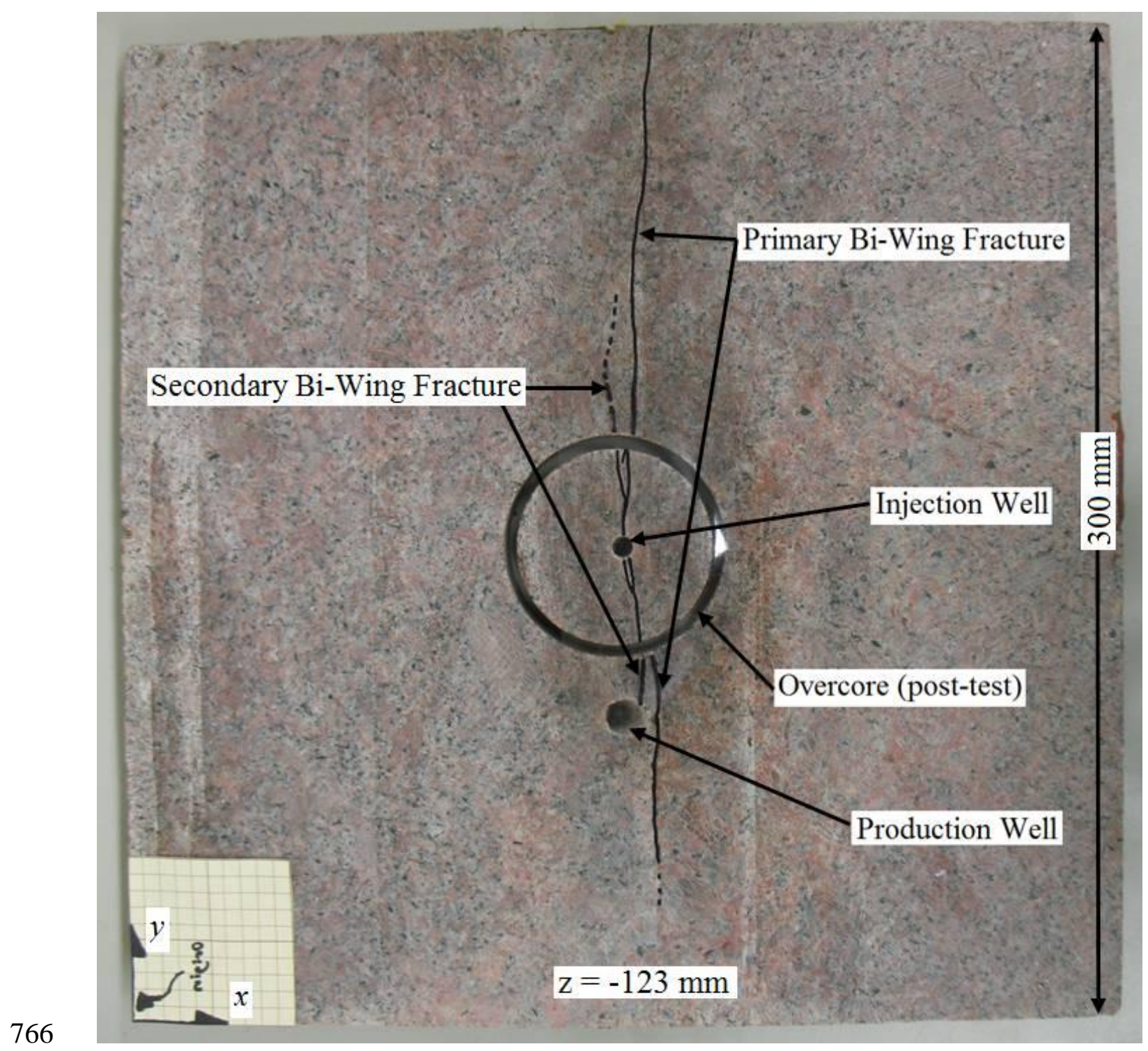

767 Fig. 13. G01-90 cross-section from $123 \mathrm{~mm}$ depth showing four fracture wings. 


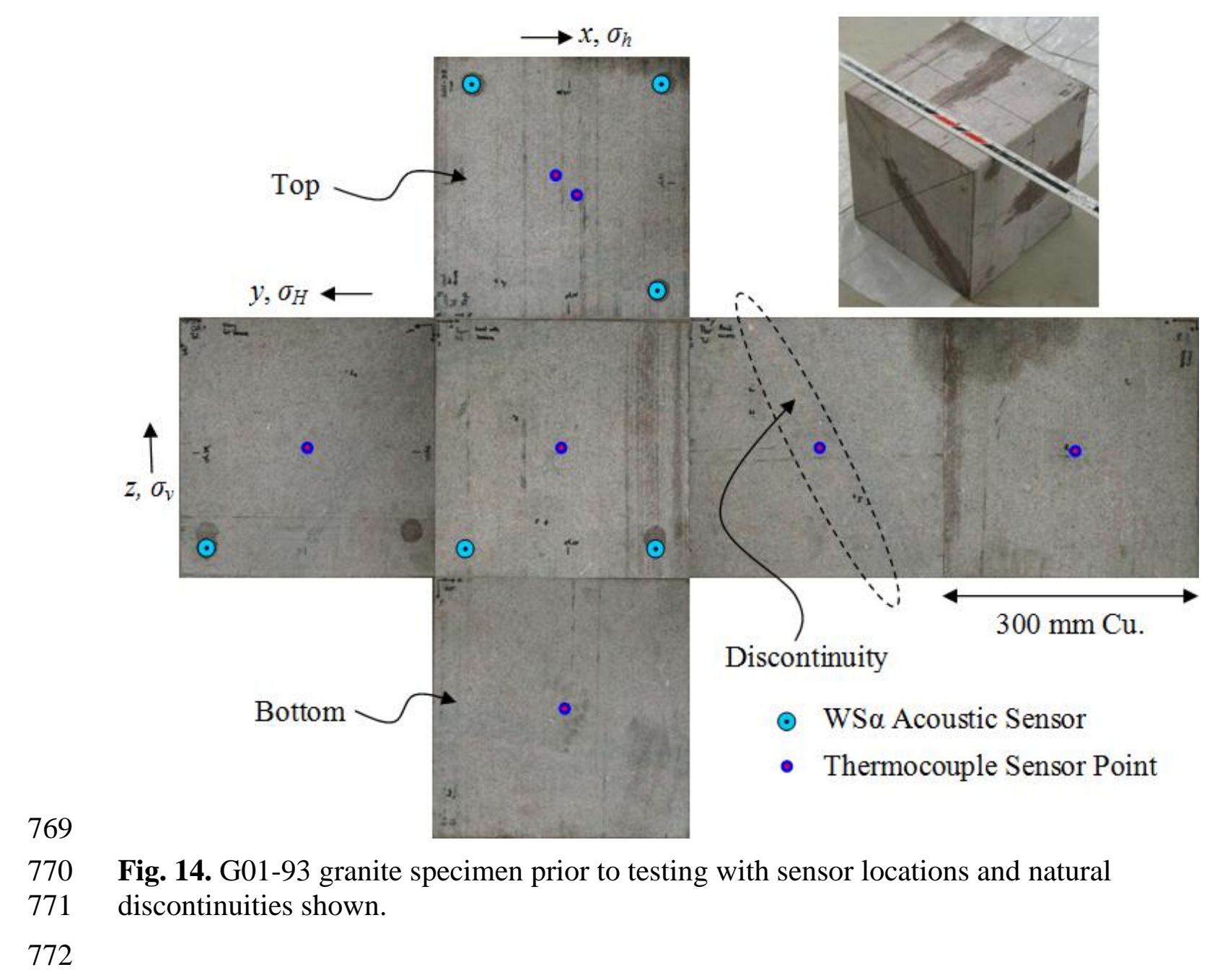




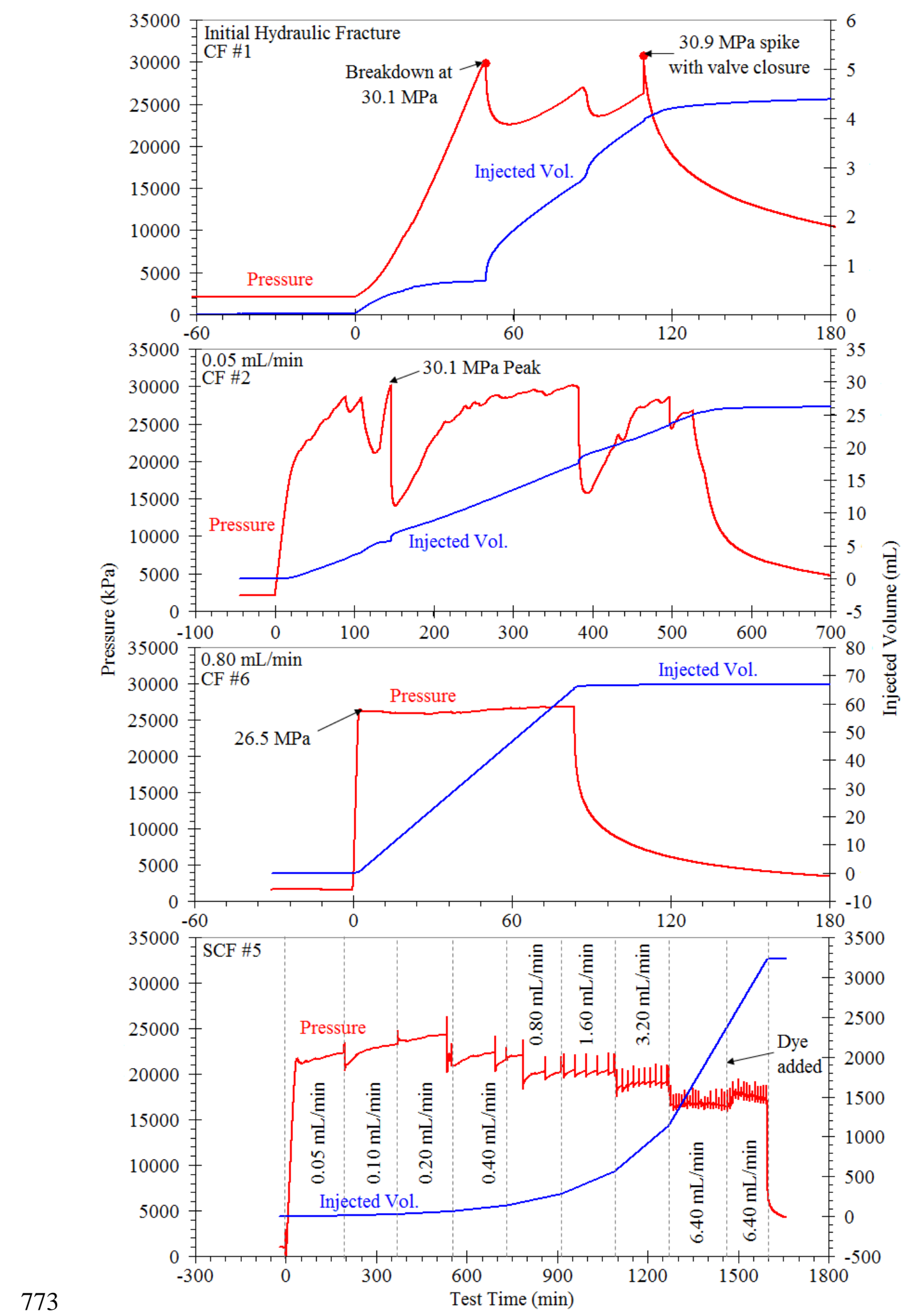

Fig. 15. G01-93 injection pressures and fluid volumes. 


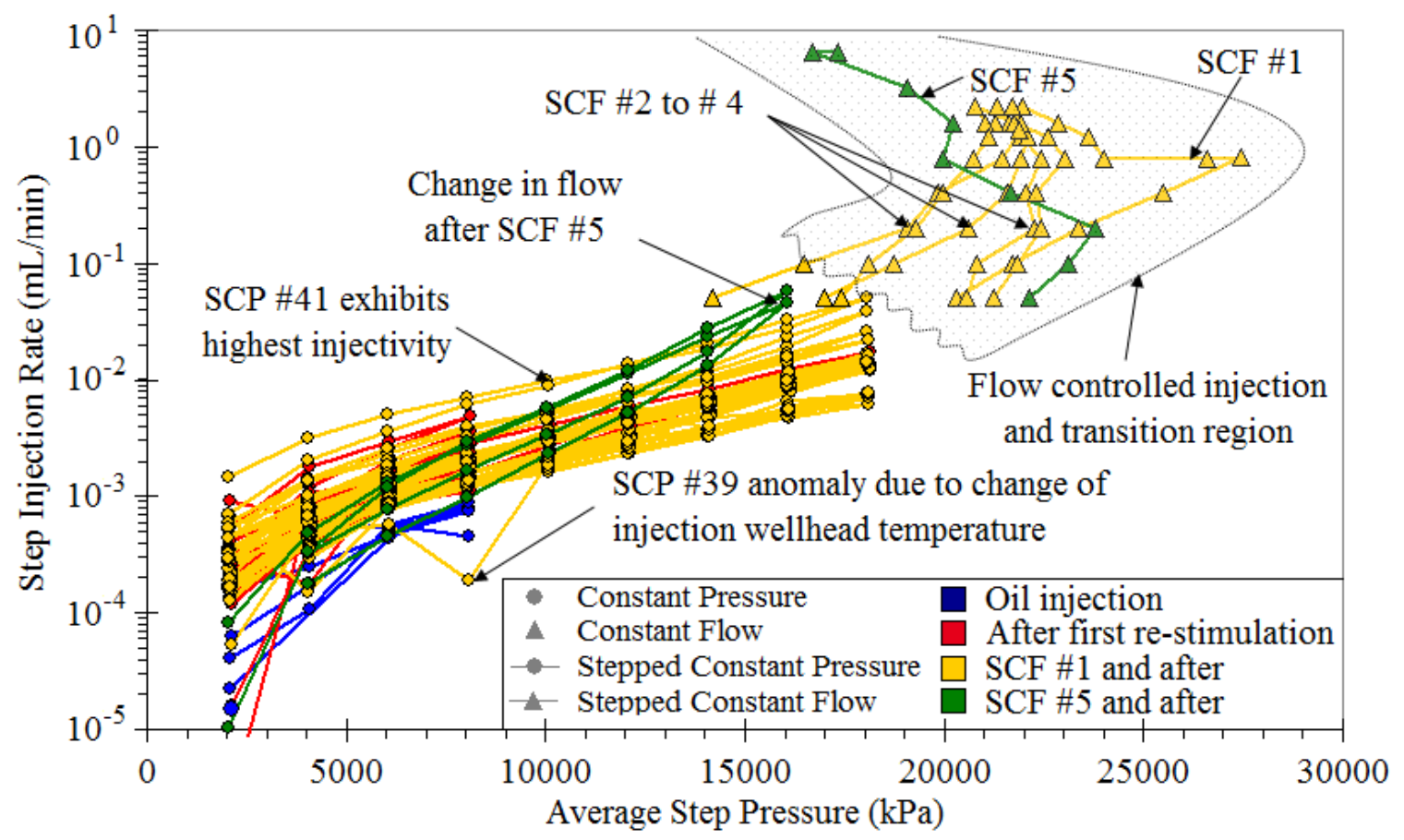

Average Step Pressure $(\mathrm{kPa})$

777 Fig. 16. Compiled analyzed data from SCP and SCF injections in G01-93. 

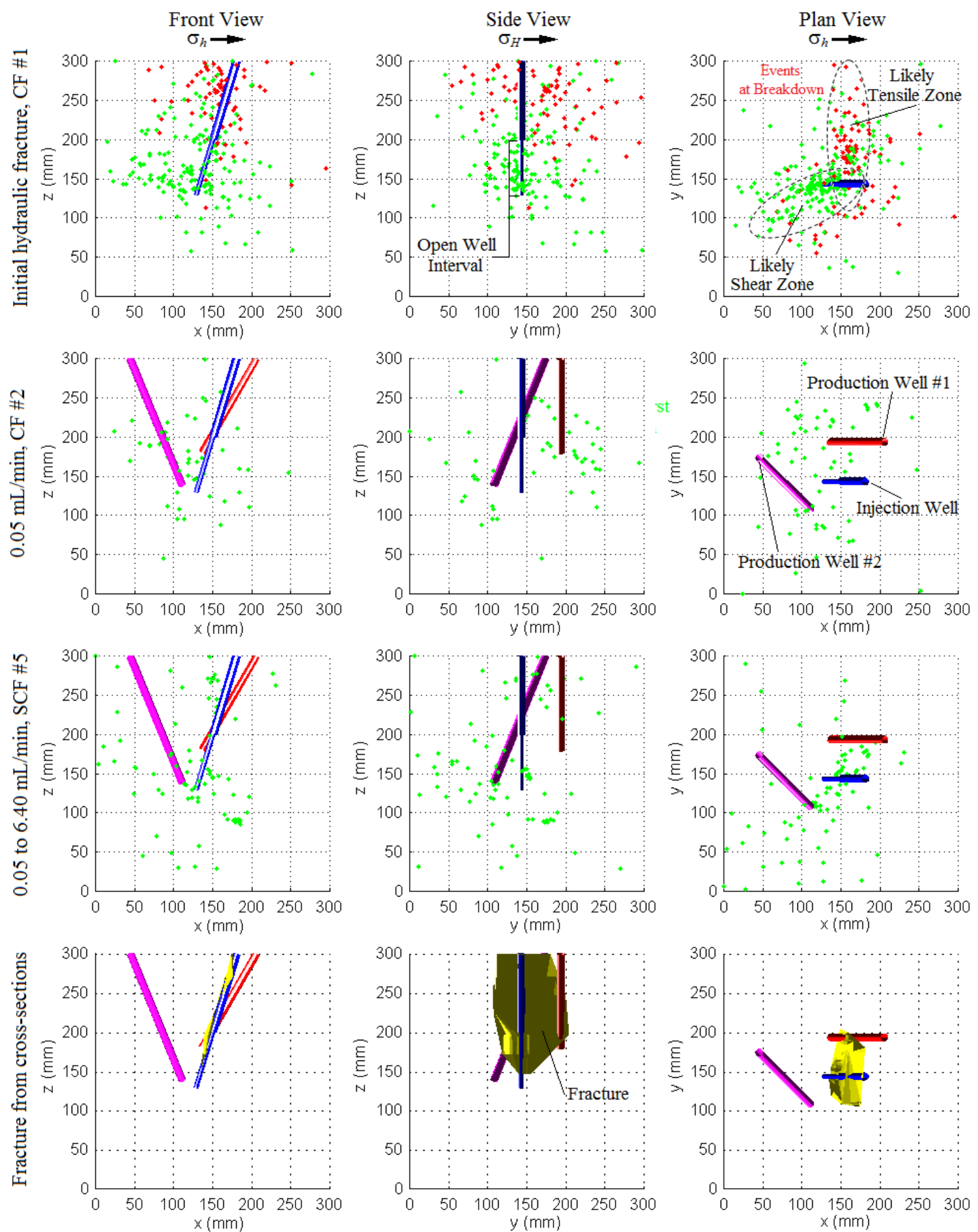

Fig. 17. AE events recorded during G01-93 stimulations and observed final fracture geometry with interpolated intersections between the wells and fractures. 


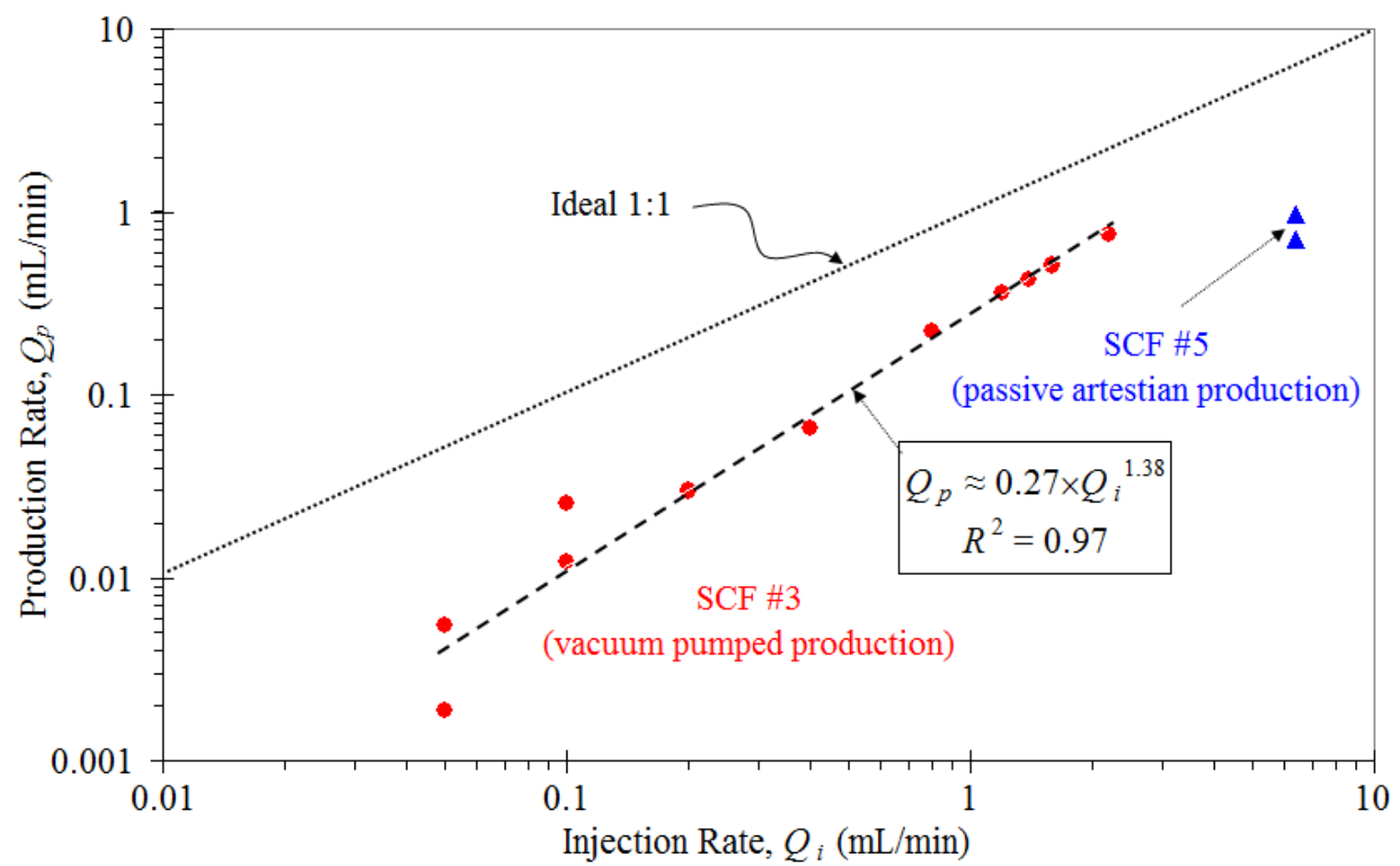

782

783 Fig. 18. Fluid production rates from G01-93.

784 


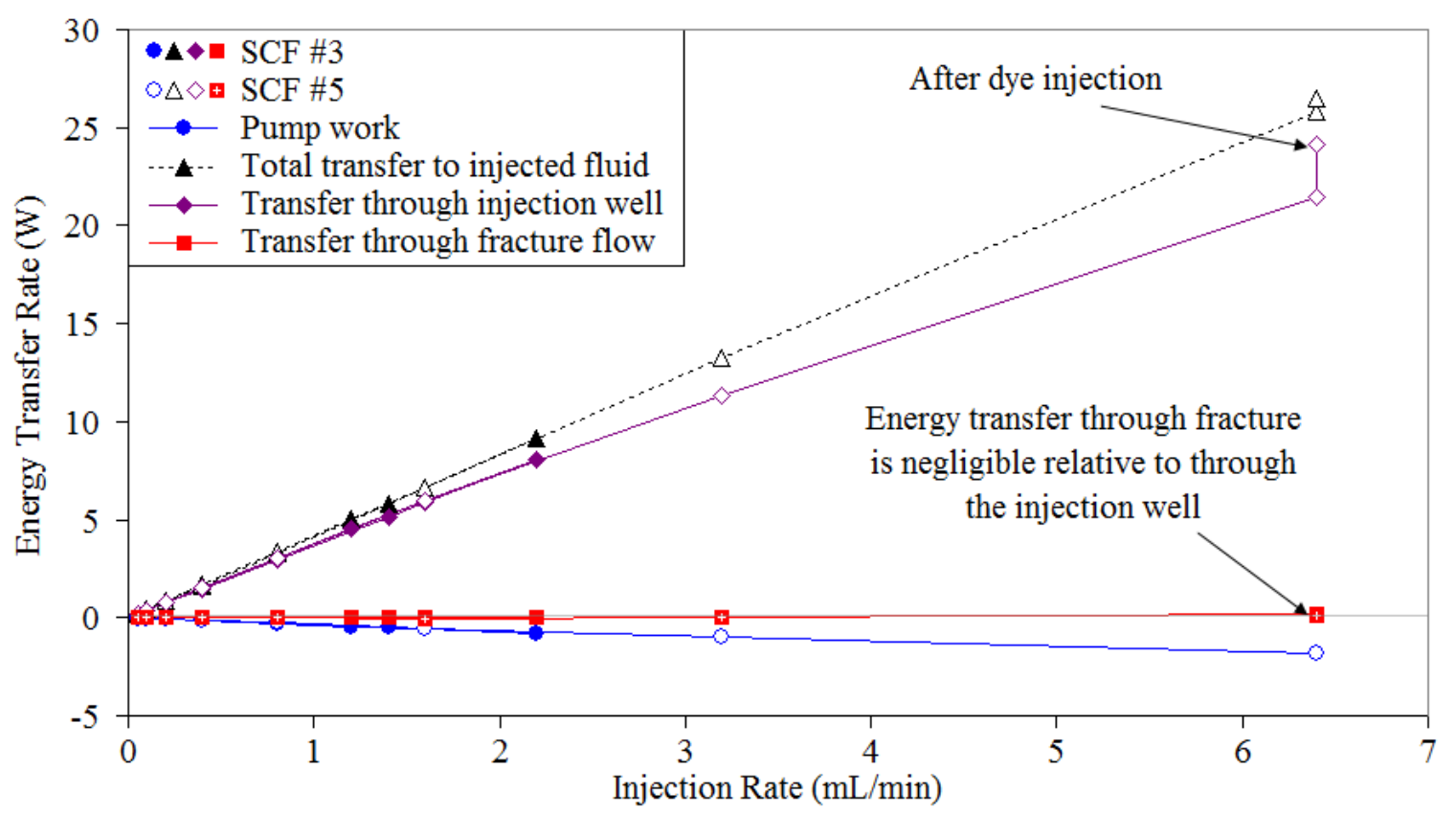

785

786 Fig. 19. Rate of energy transfer through selected zones in G01-93. 


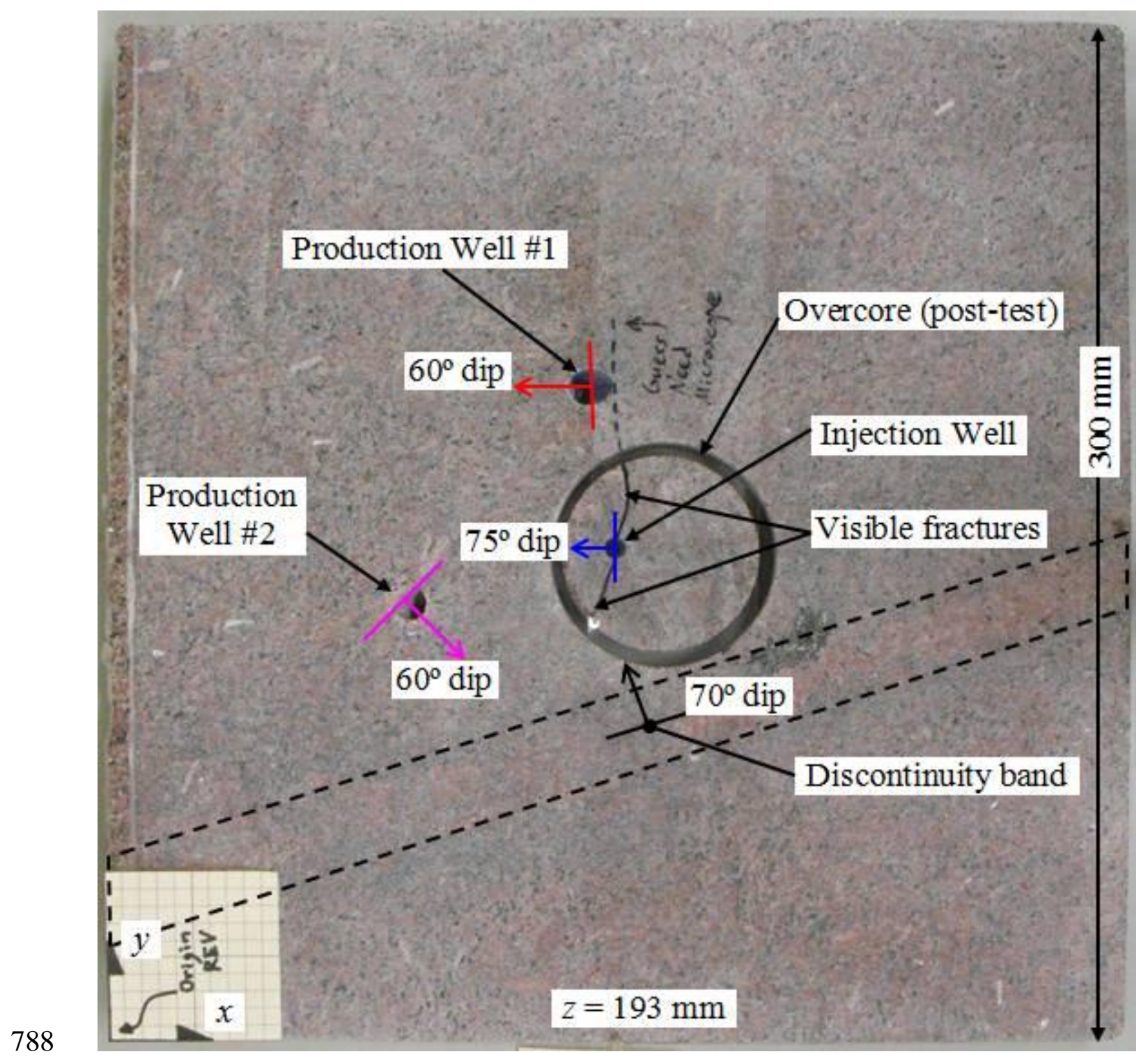

789 Fig. 20. G01-93 cross-section at $103 \mathrm{~mm}$ depth highlighting location of discontinuity. 